\title{
金属卟啉仿生催化烃类 $\mathbf{C}-\mathbf{H}$ 键氧化活化的基础研 究和应用进展
}

\author{
刘强，郭灿城* \\ 先进催化教育部工程研究中心; 湖南大学化学化工学院, 长沙 410082 \\ *通讯作者, E-mail: ccguo@hnu. edu.cn \\ 收稿日期: 2012-03-30; 接受日期: 2012-06-30; 网络版发表日期: 2012-08-06 \\ doi: $10.1007 / \mathrm{s} 11426-012-4739-\mathrm{y}$
}

\begin{abstract}
摘要金属卟啉模拟细胞色素 P450酶仿生催化烃类 C-H 键氧化活化方法在生产应用中存在 催化剂合成高成本和催化低效率等问题. 物理有机化学的基本原理和研究方法可应用于金属卟 啉仿生催化烃类 $\mathrm{C}-\mathrm{H}$ 键氧化活化的反应和过程. 通过高效大批量合成金属卟啉的新方法、可工 业化分子氧活化新方法和提高金属卟啉催化效率的研究, 可将烃类 $\mathrm{C}-\mathrm{H}$ 键氧化活化方法应用 于大宗化学品生产的金属卟啉仿生催化. 本文结合本课题组相关工作对上述内容进行了综述.

\author{
关键词 \\ 金属叶啉 \\ 仿生催化 \\ 机理 \\ 应用
} $\mathrm{C}-\mathrm{H}$ 键活化
\end{abstract}

\section{1 引言}

碳氢化合物氧化工业对我国国计民生影响重大. 近年来, 我国化工产品产值占全国 GDP 的比例稳定 在 18\% 20\%, 而碳氢化合物氧化产品的规模占我国 全部化工产品的 $30 \%$. 碳氢化合物氧化涉及烃类 $\mathrm{C}-\mathrm{H}$ 键氧化活化问题 ${ }^{[1-4]}$. 在工业应用上, 分子氧氧 化烃类 $\mathrm{C}-\mathrm{H}$ 键活化方法比其他氧化方法更受青睐. 通常, 烃类 $\mathrm{C}-\mathrm{H}$ 键氧化活化可以通过气固相或者气 液相空气氧化过程来实现, 但由于烃类 $\mathrm{C}-\mathrm{H}$ 键气固 相空气氧化需要高温且选择性差, 目前大宗含氧有 机化学品主要采用分子氧液相氧化工艺 ${ }^{[5,}$. 6] 即使如 此, 烃类 $\mathrm{C}-\mathrm{H}$ 键空气液相氧化的效率仍然很低. 例 如, 目前全球最先进的空气氧化环已烷制备 KA 油 (环己醇和环己酮的混合物)工艺, 环己烷转化率仅有

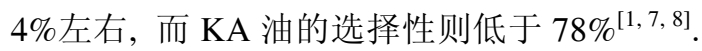

随着国际社会对生存环境和可持续发展的日益 重视 ${ }^{[9 \sim 11]}$, 新型分子氧氧化活化烃类 $\mathrm{C}-\mathrm{H}$ 键技术的 发展取得了重要进展, 并有可能取代传统碳氢化合 物氧化工艺, 成为化学化工领域创新性发展的重要
研究方法 ${ }^{[12 ~ 14]}$. 自然界中血红素蛋白可以作为氧载 体活化分子氧, 并催化氧化降解生命体中的有机化 合物 ${ }^{[15,16]} .20$ 世纪 60 年代以来, 人们以工业化应用 上述生物氧化过程为目标, 开始模拟血红素蛋白活 化分子氧研究, 与生物固氮和光合作用模拟相关研 究形成了国际三大生物氧化应用技术 ${ }^{[17 \sim 24]}$.

细胞色素 P450(CYP450)单充氧酶是广泛存在于 生物体内的一类含铁卟啉血红素蛋白, 可在温和条 件下活化分子氧并对惰性 $\mathrm{C}-\mathrm{H}$ 键实现羟基化 ${ }^{[25]}$. 但 是由于 CYP450 酶对情性 C-H 键的温和羟基化需要 经历复杂的多步单电子转移过程, 并且抗氧化性和 热稳定性差, 容易失活, 将 CYP 450 酶直接应用于碳 氢化合物氧化工业还非常困难 ${ }^{[26]}$.

1979 年, 美国普林斯顿大学 Groves 教授 ${ }^{[27]}$ 首次 提出四苯基铁卟啉( $\mathrm{TPPFeCl}$-PhIO-烷烃的仿生催化 氧化体系. 该体系采用 CYP450酶的活性中心结构金 属卟啉作为仿生催化剂, 被广泛应用于温和条件下 羟基化惰性烃类 $\mathrm{C}-\mathrm{H}$ 键的模拟研究和 CYP450 酶催 化氧化机理研究 ${ }^{[28 ~ 45]}$. 目前以分子氧为氧源的 CYP450酶仿生催化模拟体系包括金属卟啉- $\mathrm{O}_{2}$-烷烃- 


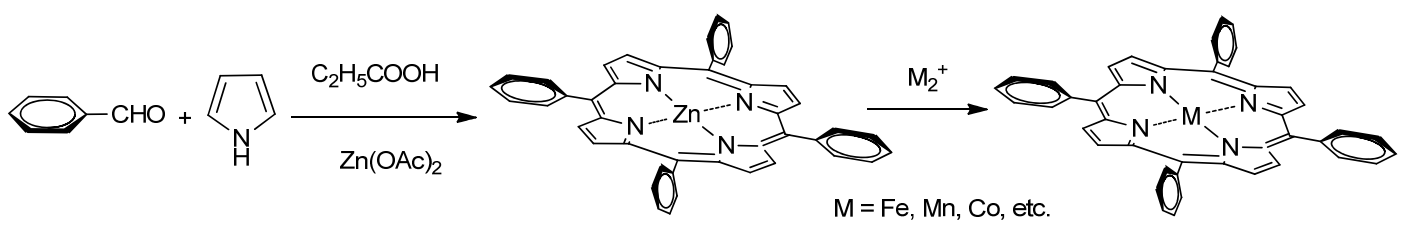

图 1 单金属卟啉一步合成法

还原剂体系、金属卟啉- $\mathrm{O}_{2}$-烷烃-光化学体系、金属卟 啉- $\mathrm{O}_{2}$-烷烃-电化学体系和多卤金属卟啉- $\mathrm{O}_{2}$-烷烃体 系. 在这些模拟体系中, Lyons 和 Ellis 等人 ${ }^{[39]}$ 提出的 多卤代金属卟啉- $\mathrm{O}_{2}$-烷烃模拟体系(即 Lyons 催化体 系)更具工业应用前景. 该体系以价廉易得的分子氧 作为氧化剂, 不需化学计量氧化剂, 也不需要还原剂 (或不加溶剂)和光电等物理化学辅助手段, 非常接近 于工业上碳氢化合物液相催化氧化反应工艺. 但目 前全氟代或多卤代卟啉的合成成本无法满足工业生 产的要求, 而且催化效率非常低 ${ }^{[28,39,40]}$. 在前人多次 改进金属卟啉合成方法的基础上 ${ }^{[46 ~ 54]}$, 我们课题组 开发了大批量简便制备单金属卟啉的一步模板合成

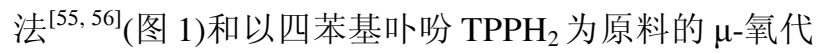
铁卟啉一步合成法 ${ }^{[57]}$ (图 2), 降低了简单金属卟啉的 生产成本.

虽然通过改进的一步合成法实现了金属卟啉由 试剂向工业产品的转化, 但金属卟啉实现对烃类的 催化氧化还存在以下问题: (1)简单金属卟啉还原电 势没有全氟代或其它多卤代卟啉的还原电势高, 温 和条件下实现分子氧的活化仍然存在成本高的问题; (2)活化分子氧产生的高价铁氧中间体(图 3 中(5)), 容 易与铁卟啉二聚成 $\mu$-氧双铁卟啉而失活(图 3 中反应 A) ${ }^{[39] ;}$ (3)芳环和吡咯环上含有诸多 $\mathrm{C}-\mathrm{H}$ 键, 容易被 活性高价铁氧中间体自氧化破环而失活, 降低了催 化效率 (图 3 中反应 $\mathrm{B})^{[58,59]}$.

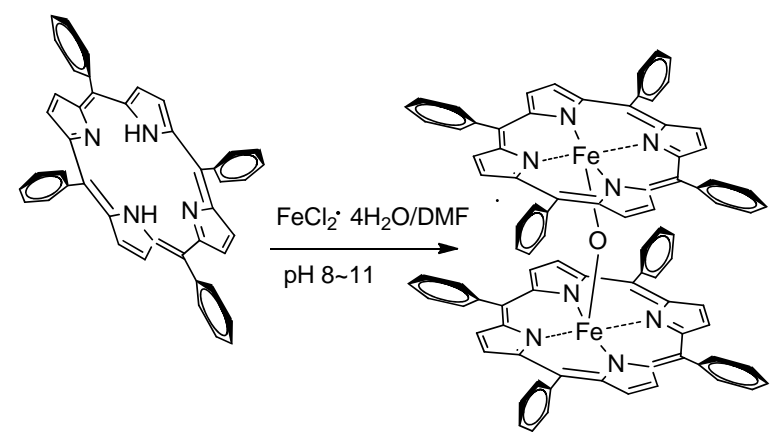

图 $2 \mu$-氧代铁卟啉一步合成法

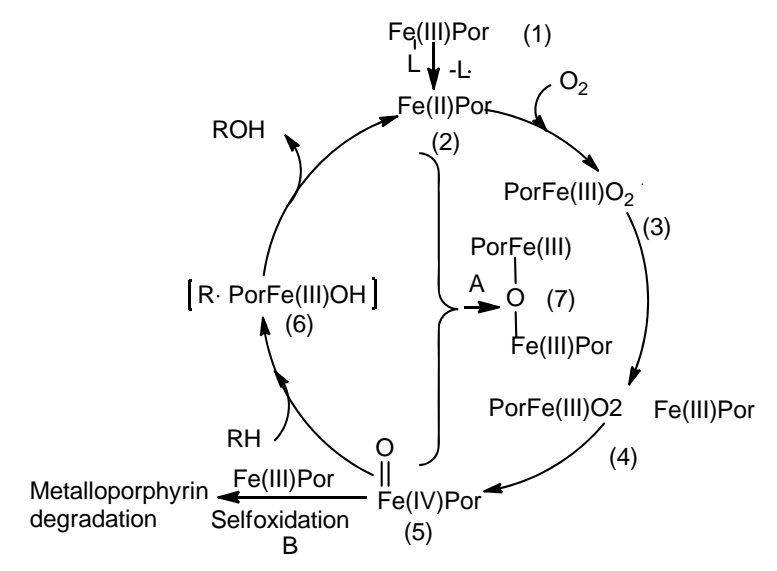

图 3 分子氧体系金属卟啉仿生催化碳氢化合物机理

上述问题导致金属卟啉仿生催化烃类 $\mathrm{C}-\mathrm{H}$ 氧化 的催化效率还非常低. 2002 年, 美国加州工学院的 Labinger 教授 ${ }^{[00]}$ 在 Nature 发表的综述中指出, “利用 生物氧化原理实现烃类化合物的氧化在理论上是可 行的, 但用于大宗化学品的生产是有问题的”.

为了在实现金属卟啉由化学试剂向工业产品转 化的同时, 进一步形成可工业应用于大宗烃类 $\mathrm{C}-\mathrm{H}$ 氧化生产化学品的先进仿生催化绿色技术, 我们课 题组将物理有机化学基本原理和研究方法应用于烃 类 $\mathrm{C}-\mathrm{H}$ 键仿生催化氧化反应, 以提高烃类 $\mathrm{C}-\mathrm{H}$ 键的 仿生催化氧化效率. 本文综述了本课题组在模拟血 红素蛋白活化分子氧过程以及金属卟啉仿生催化烃 类 $\mathrm{C}-\mathrm{H}$ 键氧化活化领域的基础研究和应用研究进展.

\section{2 金属叫啉高效催化烃类 $\mathbf{C}-\mathbf{H}$ 键氧化活化 的新方法}

金属卟啉模拟 CYP450 的活性中心催化烃类 $\mathrm{C}-\mathrm{H}$ 键氧化活化的方法, 采用空气作氧源, 催化剂无 需回收, 且条件温和、选择性高、产物分离简便. 如 果能将该方法用于工业生产, 不但能实现碳氢化合 物催化氧化技术绿色化, 还能大幅度降低工业生产 
投资和运行成本, 有可能导致传统催化氧化工业的 革命性变革. 金属卟啉催化下的烃类 $\mathrm{C}-\mathrm{H}$ 键空气氧 化活化的关键是分子氧的活化. 但是, 具有高自旋电 子价态排布的非稳定态金属卟啉才具有活化分子氧 的能力 ${ }^{[25]}$. 简单金属卟啉还原电势低, 难形成高自旋 电子排布的非稳定态结构形式, 容易转化成催化活 性低的 $\mu$-氧双金属卟啉. 另一方面, 金属卟啉配体本 身易被氧化而失去催化能力, 从而导致简单金属卟 啉不能催化活化分子氧. 采用全氟代或其他多卤代 卟啉, 能增加三价铁卟啉的还原电势, 形成高自旋电 子排布的非稳定态结构形式, 从而实现分子氧的活 化, 但催化效率非常低 ${ }^{[39,40,61]}$. 如何提高简单金属卟 啉催化活化分子氧能力, 尤其是找到 $\mu$-氧双金属卟 啉催化活化分子氧的途径, 并抑制金属卟啉自氧化, 成为提高金属卟啉催化碳氢化合物空气氧化的科学 难题.

\section{1 可工业应用的分子氧活化方法}

尽管分子氧氧化 $\mathrm{C}-\mathrm{H}$ 键的反应是放热反应，但 三线态分子氧的基态 $\left({ }^{3} \mathrm{O}_{2}\right)$ 在最高占据的反键 $\pi *$ 轨道 有两个未成对电子, 与自旋成对的单线态碳氢键的 反应是自旋禁阻的反应 ${ }^{[15,}{ }^{22]}$. 而在生命体内

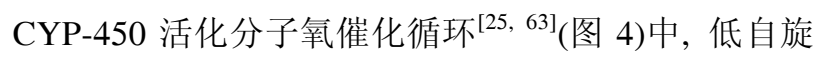
的铁卟啉(1)先失去水分子后形成高自旋的铁卟啉(2), 并进一步在得到一个电子条件下还原成二价铁吓啉 (3), 后者通过与分子氧形成铁卟啉和分子氧的加合 物 (4). 该加合物进一步接受一个电子使分子氧形成 高活性的高价铁氧正离子自由基(7), 从而实现从惰 性分子氧到活性原子氧的转变. 上述过程不需克服 分子氧基态 ${ }^{3} \mathrm{O}_{2}$ 激发形成单线态氧 $\left({ }^{1} \mathrm{O}_{2}\right)$ 所需要的高能 垒, 分子氧活化可在室温进行.

在简单金属卟啉模拟 CYP450 酶活化分子氧的 模型中, 非卤代的简单金属卟啉的还原多借助化学 还原 ${ }^{[47,64,65]}$, 如连二硫酸钠、 $\mathrm{NaBH}_{4}$ 、乙酰丙酮铬(II) 等, 借助光或者电进行化学还原 ${ }^{[66-69]}$. 此外引入强轴 纵配体, 如吡啶或咪唑等, 三价铁卟啉容易自还原成 六配位的二价铁卟啉 ${ }^{[47,70,71]}$. Haber 等人 ${ }^{[41]}$ 发现简单 锰卟啉催化分子氧氧化环辛烷反应中, 轴纵配体参 与下可引发三价锰卟啉还原成二价锰卟啉(式(1)). 但 这些方法由于经济原因难以工业化. 加热技术是工 业上的一种常规技术. 本实验室的工作表明, 将简单 金属卟啉在并不太高的温度下 $\left(120{ }^{\circ} \mathrm{C}\right)$ 通过热解还

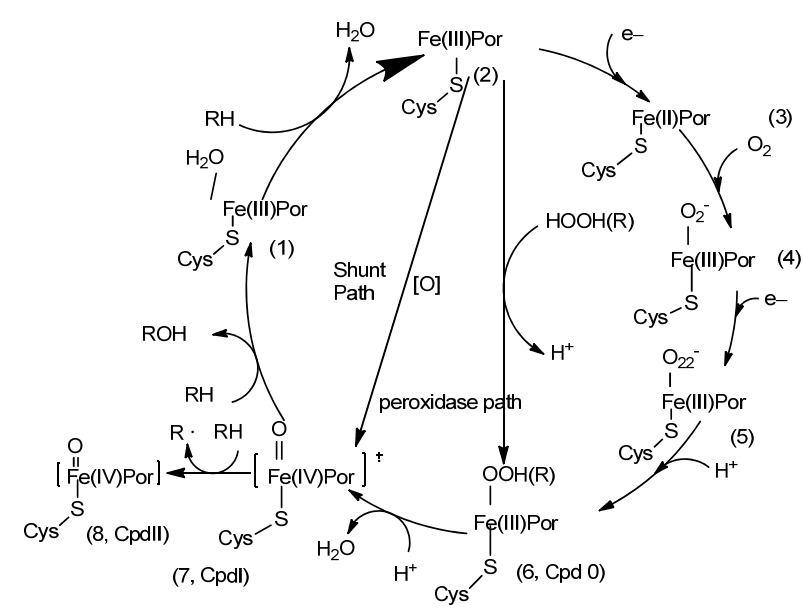

图 4 细胞色素 P450 酶催化循环

原, 也可以实现三价铁卟啉到二价铁卟啉的转化 ${ }^{[72]}$ 并进一步实现空气对惰性碳氢键的仿生催化空气氧 化活化(式(2)).

$$
\begin{aligned}
& \mathrm{PMn}{ }^{\mathrm{III} X}+\mathrm{C}_{8} \mathrm{H}_{8} \stackrel{\triangle}{\longrightarrow} \mathrm{PMn}^{\prime \prime}+\mathrm{C}_{8} \mathrm{H}_{7}+\mathrm{HX} \\
& \mathrm{X}=\mathrm{F}^{-}, \mathrm{Cl}^{-}, \mathrm{Br}^{-}, \mathrm{I}^{-}, \mathrm{OH}^{-}, \mathrm{CH}_{3} \mathrm{COO}^{-}
\end{aligned}
$$

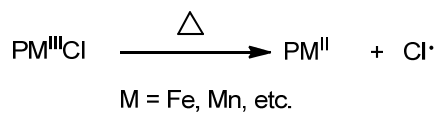

$\mathrm{KOH}$ 可促进金属卟啉 $\mathrm{Rh}^{\mathrm{III}}$ (TTP)Cl 在 $120{ }^{\circ} \mathrm{C}$ 热 解还原成 $66 \%$ 的 $\left.\mathrm{Rh}^{\mathrm{II}}(\mathrm{TPP})\right]_{2}{ }^{[73]}$. 理论和计算化学计 算进一步表明, 对于金属卟啉仿生催化烃类 $\mathrm{C}-\mathrm{H}$ 键 氧化活化过程, 金属叶啉热解还原过程在能量上是 有利的. 电子由卟啉环向金属原子 $\mathrm{d}$ 轨道转移, 再经 金属原子 $\mathrm{d}$ 轨道进入 $\mathrm{O}_{2}$ 前线分子轨道. 对比实验证 明, 在相同的温度下, 如果没有金属卟啉存在, 惰性 碳氢键的空气氧化并不能发生. 采用金属盐作催化 剂, 其转化率也低于金属卟啉 ${ }^{[74]}$.

\section{$2.2 \mu$-氧双金属卟啉对分子氧的活化}

二价铁卟啉在活化分子氧后容易生成高价铁氧 中间体, 后者容易与二价铁卟啉二聚成 $\mu$-氧双铁卟 啉而失活 ${ }^{[1]}$, 如图 3 中反应 A 所示.

$\mu$-氧简单双铁卟啉 $(\mathrm{TPPFe})_{2} \mathrm{O}$ 能催化 $\mathrm{O}_{2}$ 氧化烯 烃得到烯酮产物 ${ }^{[75]}$, 在 $\mathrm{CH}_{2} \mathrm{Cl}_{2}$ 溶液中也能催化 $\mathrm{PhIO}$ 对环已烯的羟基化 ${ }^{[76]}$, 但催化活性很低. 高位阻的多 卤代铁吓啉的 $\mu$-氧二聚体具有催化氧化烷烃的能力, 但简单金属卟啉的 $\mu$-氧二聚体对烷烃的氧化并不具 备催化活性 ${ }^{[61]}$. 本课题组的研究工作表明, 在 $\mathrm{CH}_{2} \mathrm{Cl}_{2}$ 溶剂中, 经适当时间后, 双金属卟啉具有催化 
$\mathrm{PhIO}$ 羊基化环己烷的能力, 且比单铁卟啉的催化活 性还高 ${ }^{[77,78]}$. 双铁卟啉的催化活性与溶剂性质有关 (表 1). 溶剂极性越小, 环已醇和环已酮的总产率越 大, 而环己醇的选择性减小, 环己酮选择性增加, 表 明非极性溶剂有利于提高 $\mu$-氧代简单金属卟啉的催 化活性. 双铁卟啉的 ESR 研究表明, 反磁性 $(\mathrm{TPPFe})_{2} \mathrm{O}$ 在液氮温度下可转化成顺磁的 $\mathrm{TPPFeCl}^{[79]}$. 这一现象进一步说明 $(\mathrm{TPPFe})_{2} \mathrm{O}$ 可以具有催化活性, 并且可能是 $(\mathrm{TPPFe})_{2} \mathrm{O}$ 需要在非极性溶剂中需要较长 时间才能表现出催化活性的原因. 对 $\mu$-氧简单双金 属吓啉在不同氧化剂 $\left(\mathrm{PhIO}, \mathrm{H}_{2} \mathrm{O}_{2}\right)$ 下的转化研究发现, $\mu$-氧双铁卟啉 (TPPFe $)_{2} \mathrm{O}$ 在 $\mathrm{PhIO}$ 和 $\mathrm{H}_{2} \mathrm{O}_{2}$ 作用下容易 快速产生具有羟基化 $\mathrm{C}-\mathrm{H}$ 键能力的 $\mathrm{TPPFe}=\mathrm{O}$, 从而 使得双金属卟啉具催化活性. 在含氯溶剂中, 在 $\mathrm{H}_{2} \mathrm{O}_{2}$ 或 PhIO 存在下, 铁卟啉 $\mu$-氧二聚体 $(\mathrm{TPPFe})_{2} \mathrm{O}$ 易与其单体 $\mathrm{TPPFeCl}$ 之间快速转化(式(3) ${ }^{[80]}$. 反应对 $(\mathrm{TPPFe})_{2} \mathrm{O}$ 为一级.

HPLC 监测发现, $(\mathrm{TPPFe})_{2} \mathrm{O}$ 能在空气中转化为 $\mathrm{TPPFeCl}$ (式(4)). 提高反应温度可加快( $\mathrm{TPPFe})_{2} \mathrm{O}$ 转 化为 $\mathrm{TPPFeCl}$, 同时减少 $\mu$-氧双金属卟啉的催化诱导 期, 增加反应速率 ${ }^{[77]}$, 如表 2 所示.

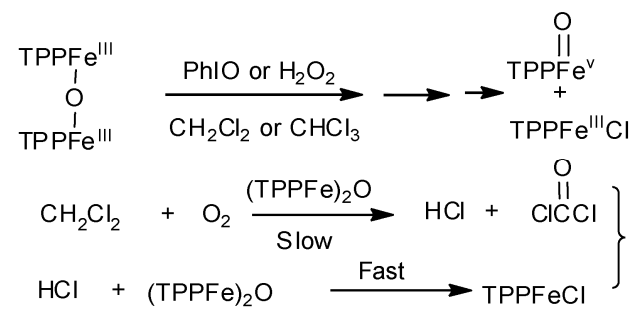

表 1 溶剂对转化速率常数的影响 ${ }^{\text {a) }}$

\begin{tabular}{cccccc}
\hline 溶剂 & DCM & 甲醇 & 丙䀦 & 苯 & 环己烷 \\
\hline 反完成时间 $(\min )$ & 2 & 1 & 1 & 2 & 16 \\
总产率 $(\%)$ & 14.97 & 6.54 & 12.53 & 29.13 & 62.60 \\
$k \times 10^{4}(\mathrm{~mol} / \mathrm{L} \cdot \mathrm{min})$ & - & - & 16.80 & 9.45 & 4.42 \\
\hline
\end{tabular}

a) $5 \mathrm{~mL}$ 环已烷, $5 \mathrm{~mL}$ 溶剂, $4.5 \times 10^{-4} \mathrm{~mol} \mathrm{PhIO}, 7.5 \times 10^{-6} \mathrm{~mol}$ $(\mathrm{TPPFe})_{2} \mathrm{O}, 25^{\circ} \mathrm{C}$.

表 2 温度对转化速率常数的影响 ${ }^{\text {a) }}$

\begin{tabular}{cccc}
\hline$T(\mathrm{~K})$ & 293 & 298 & 303 \\
\hline $1 / T \times 10^{3}$ & 3.413 & 3.356 & 3.300 \\
$k\left(\mathrm{~min}^{-1}\right)$ & 0.04383 & 0.06701 & 0.1033 \\
$-\ln \kappa$ & 3.1274 & 2.7029 & 2.2701 \\
\hline
\end{tabular}

a) $k$ 为三次实验所测平均值, 相对误差 $<2 \%$

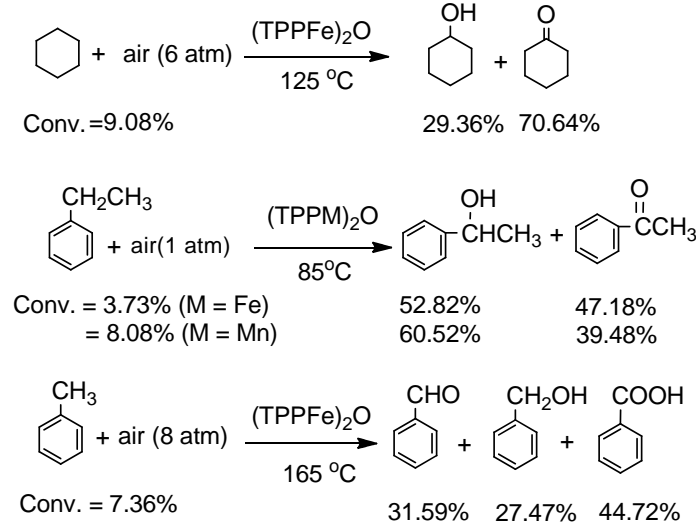

图 $5 \mu$-氧代双铁卟啉催化的烃类空气氧化

在以空气为氧化剂的催化烃类氧化体系中, 也 发现类似现象. 提高反应温度达 $80{ }^{\circ} \mathrm{C}$ 以上, 经过 $1 \mathrm{~h}$ 的诱导期后，无催化活性的简单 $\mu$-氧双金属卟啉对 乙苯 ${ }^{[81]}$ 和甲苯 ${ }^{[82]}$ 的苄基 $\mathrm{sp}^{3} \mathrm{C}-\mathrm{H}$ 键以及环己烷 $2^{\circ} \mathrm{C}-\mathrm{H}$ 键 ${ }^{[83]}$ 也表现出较高的催化活性(图 5), 进一步 对单金属卟啉和 $\mu$-氧双金属卟啉催化活性对比研究 发现, $\mu$-氧双金属卟啉在以 PhIO 或空气为氧化剂的 仿生 催化体系中表现出比单金属卟啉更好的催化活 性 ${ }^{[77,78,81 ~ 83]}$. 这与 $\mu$-氧双金属卟啉具有比单金属卟 啉更强的抗氧化性能有关 ${ }^{[42]}$.

\section{3 金属卟啉仿生催化烃类 $\mathbf{C}-\mathbf{H}$ 键氧化活化反应 的构效关系}

金属卟啉催化烃类 $\mathrm{C}-\mathrm{H}$ 键效率普遍较低. 目前, 提高金属卟啉仿生催化效率主要有 3 种方法,一是在 吓啉吡咯环上和/或苯环上引入强吸电子取代基 ${ }^{[40]}$, 二是在金属离子上引入吸电子轴纵配体 ${ }^{[84]}$, 三是引 入高位阻取代基或载体 ${ }^{[85,86]}$. 为提高金属卟啉催化 效率, 科学家们从金属卟啉结构与其催化性能关系 入手, 利用线性自由能关系考察了金属卟啉仿生催

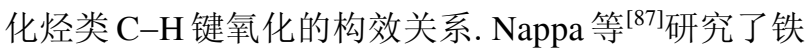
卟啉催化 $\mathrm{PhIO}$ 差基化环已烷 $\mathrm{C}-\mathrm{H}$ 键中取代基效应和 位阻效应对反应的影响. 通过对 5 种取代单铁卟啉的 线性自由能关系(LFER)研究发现, $\rho=0.26 \pm 0.02, \rho$ 为 正值表明吸电子取代基有利于催化反应. 我们对 40 种取代单金属卟啉和 $\mu$-氧双金属卟啉仿生催化 PhIO 氧化环已烷反应构效关系的研究结果表明, 吸电子 取代基有利于催化反应. 金属卟啉催化氧化过程的 Hammett 关系的 $\rho$ 全为正值, 其数值在 $0.34 \sim 0.53$ 之 


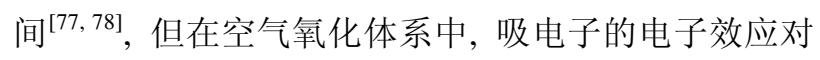
$\mu$-氧双铁卟啉和 $\mu$-氧双锰吓啉催化活性的影响不同. 含吸电子取代基的单金属卟啉和 $\mu$-氧双铁卟啉的催 化活性高 ${ }^{[88]}$, 而吸电子取代基和给电子取代基都有 助于提高 $\mu$-氧双锰卟啉的催化活性 ${ }^{[89]}$.

单晶结构和电化学研究显示 ${ }^{[40]}$, 吸电子取代基 在卟啉吡咯环上的引入, 不仅增加了第二代金属卟 啉和第三代金属卟啉环自身的位阻, 同时增加了其 自身的氧化电位, 避免了自氧化. 我们通过定量催化 活性关系研究 (QSAR) 发现, 由金属卟啉模型获得的 前线分子轨道能 $E_{\mathrm{LUMO}-\mathrm{b}}$ 与实验获得的金属卟啉催化 环己烷羟基化反应速率呈线性关系(如图 6) ${ }^{[90]}$. 这表 明前线分子轨道能对金属卟啉催化活性有重要影响, 吸电子取代基可以降低 $E_{\mathrm{LUMO}-\mathrm{b}}$, 同时还可分散卟啉 环上金属中心电荷, 从而增强了金属卟啉的催化活 性.

除了吓啉环配体外, 轴纵配体也是影响金属卟 啉催化性能的重要因素. 吡啶和咪唑等含氮化合物 是模拟 CYP450 酶中半胱氨酸和辣根过氧化物酶中 组氨酸的良好轴纵配体, 不仅可以改善催化剂的选 择性和反应活性, 还可以防止产生无催化活性的 $\mu-$ 氧二聚体 ${ }^{[91]}$. 我们通过金属卟啉催化活性与轴纵配 体关系的研究发现, 五配体高自旋电子排布的 $\mathrm{TPPFeCl}(S=5 / 2)$ 与强配体咪唑等配位后转化成低自 旋排布 $(S=1 / 2)$ 后, 失去了催化活性 ${ }^{[92]}$; 而低自旋电 子排布的 TPPCo(II) $(S=1 / 2)$ 与吡啶形成的高自旋的 五配体络合物 $(S=3 / 2)$, 具有催化活性 ${ }^{[93]}$. 其他强吸 电子的轴纵配体, 如 $\left(\mathrm{CF}_{3} \mathrm{SO}_{3}\right)$ 也对烷烃的羟基化具有

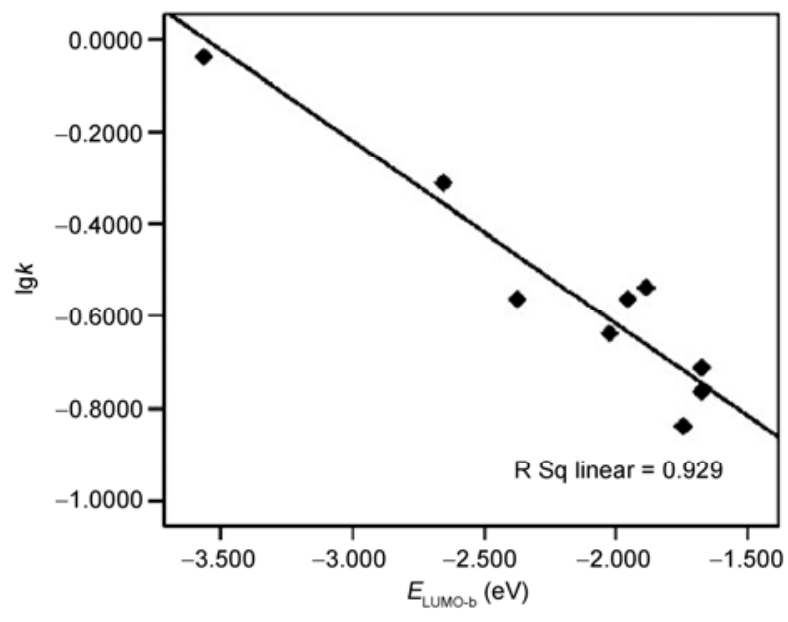

图 6 反应速率常速 $\lg k$ 与 $E_{\mathrm{LUMO}-\mathrm{b}}$ 的线性拟合
良好的催化活性 ${ }^{[94]}$. 这些结果表明, 轴纵配体可通过 改变金属卟啉的自旋状态来影响其催化能力. 由于 金属卟啉的自旋状态还受磁场的影响, 我们通过引入 外磁场发现, 外加磁场可促进顺磁性 TPPFeCl 的催化 性能, 而对反磁性 $\mu$-氧双铁卟啉呈较大负作用 ${ }^{[95]}$.

过量含氮配体与金属卟啉易形成六配体化合物 而降低了催化活性 ${ }^{[96]}$, 非氮配体 $\mathrm{X}\left(\mathrm{X}=\mathrm{F}^{-}, \mathrm{Cl}^{-}, \mathrm{Br}^{-}\right.$, $\mathrm{I}^{-}, \mathrm{MeO}^{-}, \mathrm{CF}_{3} \mathrm{CO}_{2}^{-}, \mathrm{OAc}^{-}, \mathrm{ClO}_{4}^{-}$等) 对金属卟啉 TPPFeX 催化 PhIO 羟基化环已烷和环已烯的影响表 明, 吸电子轴纵配体有助于提高金属卟啉催化活 性 $\left.{ }^{[87}, 96\right]$. 非氮轴纵配体的 Swain-Scott 亲核常数 $n$ 与 铁卟啉催化 PhIO 羟基化环己烷的反应速率 $k$ 的线性

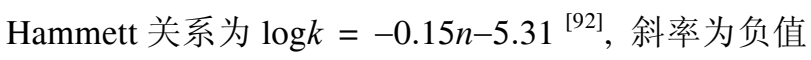
表明轴纵配体亲核性增强, 反应速率降低. TFPPFeX $\left(\mathrm{X}=\mathrm{Cl}^{-}, \mathrm{AcO}^{-}, \mathrm{OH}^{-}, \mathrm{CF}_{3} \mathrm{SO}_{3}^{-}, \mathrm{ClO}_{4}^{-}, \mathrm{NO}_{3}^{-}\right.$) 催化 $\mathrm{H}_{2} \mathrm{O}_{2}$ 氧化烷烃和烯烃中, 弱给电子的阴离子轴纵配体 (如 $\mathrm{CF}_{3} \mathrm{SO}_{3}{ }^{-}, \mathrm{ClO}_{4}^{-}, \mathrm{NO}_{3}^{-}$) 可提高 TFPPFeX 催化活性, 而 强给电子的阴离子轴纵配体 (如 $\mathrm{Cl}^{-}, \mathrm{F}^{-}, \mathrm{OAc}^{-}, \mathrm{OH}^{-}$) 降 低了 TFPPFeX 催化活性, 甚至使金属卟啉没有催化 活性 ${ }^{[96,97]}$. 但在以 PhIO 或 $m$-CPBA 为氧化剂的单加 氧体系中未呈现出类似规律 ${ }^{[98]}$. 在以 $\mathrm{O}_{2}$ 为氧化剂的 Lyons 体系中, 不同轴纵配体的锰卟啉 TTPMnX (X= $\mathrm{F}^{-}, \mathrm{Cl}^{-}, \mathrm{Br}^{-}, \mathrm{I}^{-}, \mathrm{OH}^{-}, \mathrm{OAc}^{-}$)催化氧化环辛烷的催化活 性与轴纵配体的电负性关系, 随着轴纵配体的电负 性增加, 锰卟啉催化活性也增加, 反应活性为 $\mathrm{F}^{-}>$ $\mathrm{OAc}^{-}>\mathrm{Cl}^{-}>\mathrm{OH}^{-}>\mathrm{Br}^{-}>\mathrm{I}^{-[41]}$.

采用无机或有机载体将金属卟啉固载化后再作 为催化剂, 使得本来不可循环使用的金属卟啉能够 多次循环使用. 将多氟代铁卟啉 $\mathrm{FeF}_{20} \mathrm{TPP}$ 固载在硅 胶上, 用来催化分子氧直接氧化异丁烷 $3^{\circ} \mathrm{C}-\mathrm{H}$ 键, 催 化剂转化数可达 700 , 叔丁基过氧化氢选择性达到 $44 \%{ }^{[99]}$. 通过 $\alpha, \omega$-双氨键固载在硅胶和聚苯乙烯 $(\mathrm{PVC})$ 上的 $\mathrm{Fe}\left(\mathrm{TF}_{5} \mathrm{PPCl}\right)$, 在催化分子氧氧化乙苯 $2^{\circ}$ $\mathrm{C}-\mathrm{H}$ 键时, 氧化产物与均相催化体系的氧化产物分 布类似, 只是产率下降 ${ }^{100]}$. 固载在硅胶和 $\mathrm{PVC}$ 上的 简单四苯基锰卟啉 $\mathrm{TTPMnCl}$, 在 $120{ }^{\circ} \mathrm{C}$ 和 $1 \mathrm{MPa}$ 下 催化空气氧化环辛烷 $2^{\circ} \mathrm{C}-\mathrm{H}$ 键, 主要产物为环辛酮 和环辛醇, 酮醇比 $6 \sim 8$, 含钴的金属卟啉催化活性要 高于锰卟啉 ${ }^{[101]}$. 采用可再生的生物高分子壳聚糖、 甲壳素等将金属卟啉固载化后用做环己烷、甲苯等碳 氢化合物氧化的催化剂, 反应呈准均相反应, 催化剂 可以固态回收 ${ }^{[102 ~ 104]}$. 磁性纳米固载在金属卟啉上可 
便于催化剂回收, 在环己烷氧化体系中, 磁性纳米固 载金属卟啉催化反应速率与未固载金属卟啉相当, 而环己烷转化率和催化剂转化数高于其他固载卟啉, 催化剂在外加磁场下回收, 回收率达 $99 \%{ }^{[105,106]}$.

\section{4 金属卟啉催化与自氧化的竞争}

金属卟啉仿生催化烃类 $\mathrm{C}-\mathrm{H}$ 键氧化活化的反应 中，金属卟啉在活化分子氧的同时，其自身也被体系 中存在的活性氧化物种氧化降解而发生自氧化反应. 研究表明, 金属卟啉自氧化的最初产物是由体系中 氧化物种进攻卟啉中位碳原子形成的卟啉开环产 物 ${ }^{[59,84]}$. 在金属卟啉仿生催化烃类 $\mathrm{C}-\mathrm{H}$ 键氧化的过 程中, 金属卟啉对 $\mathrm{C}-\mathrm{H}$ 键的催化活化反应与自氧化 反应是相互竞争的两个过程. 随着金属卟啉自氧化 反应的发生，金属卟啉在体系中的浓度不断减少而 导致催化效率降低.

线性自由能关系研究方法被用于研究烃类 $\mathrm{C}-\mathrm{H}$ 键氧化体系中金属卟啉仿生催化反应与自氧化的竞 争关系. 不同类型金属卟啉催化 PhIO 氧化环己烷的 反应具有类似的 Hammett 关系, 其反应常数 $\rho$ 全为正 值, 数值在 0.34 0.53 之间(表 3), 表明取代基的吸电 子效应稳定金属卟啉仿生催化 $\mathrm{C}-\mathrm{H}$ 键氧化决速步骤 的中间体结构. 但该中间体对电子效应并不敏感 ${ }^{[107]}$. 数值较小的正反应常速与文献提出的高价金属氧正 离子自由基中间体 $\left[\mathrm{PFe}^{\mathrm{IV}}=\mathrm{O}\right]^{+}$结构一致 ${ }^{[108]}$.

在没有碳氢化合物存在下，金属卟啉能被 $\mathrm{PhIO}$ 氧化而发生自氧化反应。不同金属离子的 $\mathrm{TPPM}(\mathrm{III}) \mathrm{Cl}(\mathrm{M}=\mathrm{Fe}, \mathrm{Mn}, \mathrm{Cr})$ 的自氧化动力学表明, 反应对 $\mathrm{TPPFeCl}$ 和 $\mathrm{TPPCrCl}$ 都为二级反应, 而对 $\mathrm{TPPMnCl}$ 为一级反应 ${ }^{[107]}$. 这表明锰卟啉可能与铁、 铬卟啉的自氧化途径有所不同. 金属卟啉自氧化反 应的 Hammett 关系见表 $4^{[107,109 \sim 112]}$. 对于单金属卟啉, 在卟啉环上无论引入吸电子取代基还是给电子取代 基, 都使自氧化反应速率加快, 获得的是 $\mathrm{V}$ 型 Hammett 曲线. 而对于 $\mu$-氧双铁卟啉, $\rho=0.3973$, 表 明吸电子取代基可以加速自氧化反应速率. PhIO 氧 化取代 $\mu$-氧双锰卟啉反应复杂, 而且速度很快, 无法 用常规手段研究其反应动力学. $\mathrm{H}_{2} \mathrm{O}_{2}$ 代替 $\mathrm{PhIO}$ 氧化 取代 $\mu$-氧双锰卟啉的 Hammett 关系为 $\lg k=-0.6315 \sigma$ $+0.1384^{[101]}$.

与取代 $\mu$-氧双铁卟啉不一样, $\mathrm{H}_{2} \mathrm{O}_{2}$ 氧化 $\mu$-氧双锰 卟啉的反应常速为负值表明, 在卟啉环上引入给电
表 3 金属卟啉催化 $\mathrm{PhIO}$ 羟基化环己烷线性自由能关系 a)

\begin{tabular}{lll}
\hline 金属卟啉 & Hammett 方程 & 相关系数 \\
\hline $\mathrm{RTPPFeCl}$ & $\log k=0.46 \sigma-5.03$ & 0.9963 \\
$(\mathrm{RTPPFe})_{2} \mathrm{O}$ & $\log k=0.34 \sigma-5.00$ & 0.9927 \\
$\mathrm{RTPPMnCl}$ & $\log k=0.47 \sigma-4.98$ & 0.9978 \\
$(\mathrm{RTPPMn})_{2} \mathrm{O}$ & $\log k=0.53 \sigma-4.90$ & 0.9972 \\
\hline
\end{tabular}

a) $5 \mathrm{~mL}$ 环己烷, $5 \mathrm{~mL}$ 苯, $4.5 \times 10^{-4} \mathrm{~mol} \mathrm{PhIO}, 3.0 \times 10^{-5} \mathrm{~mol}$ 金 属卟啉, $25{ }^{\circ} \mathrm{C}$

表 4 金属卟啉自氧化线性自由能关系 ${ }^{a)}$

\begin{tabular}{clc}
\hline 金属卟啉 & \multicolumn{1}{c}{ Hammett 方程 } & 相关系数 \\
\hline RTPPFeCl & $\log k_{2}=1.7106 \sigma+3.4326$ (吸电子取代基) & 0.9989 \\
& $\log k_{2}=-1.5734 \sigma+3.4396$ (给电子取代基) & 0.9981 \\
$(\mathrm{RTPPFe})_{2} \mathrm{O}$ & $\log k_{1}=0.3973 \sigma-0.5682$ & 0.9942 \\
$\mathrm{RTPPMnCl}$ & $\log k_{1}=0.7025 \sigma-0.5668$ (吸电子取代基) & 0.9987 \\
& $\log k_{1}=-2.4870 \sigma-0.5668$ (给电子取代基) & 0.9990 \\
\hline
\end{tabular}

a) $5.26 \times 10^{-3} \mathrm{~mol} / \mathrm{L} \mathrm{PhIO}, 1.5 \times 10^{-5} \mathrm{~mol} / \mathrm{L}$ 金属叶啉, $25{ }^{\circ} \mathrm{C}$

子基有助于增加氧化反应速率.上述研究结果表明, 对于单金属卟啉，引入吸电子取代基可减少金属卟 啉的自氧化反应速率; 而对于双金属卟啉, 采用带吸 电子取代基的 $\mu$-氧双铁卟啉和带给电子取代基的 $\mu$ 氧双镇卟啉有助于减少金属卟啉的自氧化.

金属卟啉仿生催化烃类 $\mathrm{C}-\mathrm{H}$ 键活化氧化的反应 中, 高价金属氧正离子自由基 $\left[\mathrm{PFe}^{\mathrm{IV}}=\mathrm{O}\right]^{+}$是分子氧 的主要活性物种. 金属卟啉仿生催化烃类 $\mathrm{C}-\mathrm{H}$ 键氧 化活化的过程中，反应产生的活性金属卟啉中间体 更容易自氧化金属卟啉环而使催化剂失活. 金属卟 啉催化与自氧化是经过同一高价金属氧正离子自由 基中间体竞争的两个过程(图 7).

比较金属卟啉对 $\mathrm{C}-\mathrm{H}$ 键的催化活化反应与自氧 化反应的 Hammett 关系可以看出, $\mu$-氧双铁卟啉催化 $\mathrm{C}-\mathrm{H}$ 键氧化活化的反应与自氧化反应的决速步骤具 有相同的中间体结构，而对于其他金属卟啉，催化 $\mathrm{C}-\mathrm{H}$ 键氧化活化的反应与自氧化反应的决速步骤并

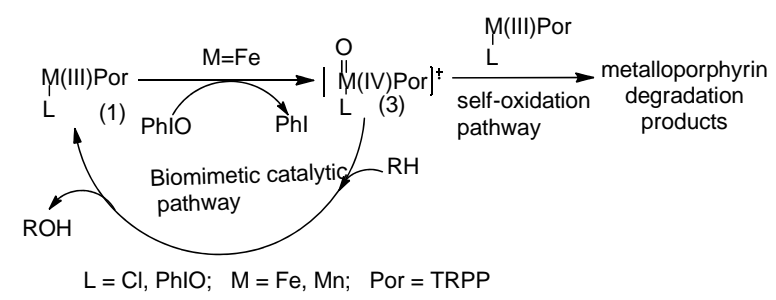

图 7 金属卟啉催化与自氧化的竞争过程 
不相同.

金属卟啉仿生催化和自氧化反应的竞争过程研 究表明，防止高价金属卟啉正离子自由基对金属卟 啉的进攻可以有效抑制金属卟啉自氧化过程. 由于 金属卟啉自氧化发生在反应产生的活性金属卟啉中 间体与原料金属卟啉之间, 选用低浓度的催化剂体 系可以有效抑制金属卟啉自氧化过程而提高金属卟 啉催化活性(表 5) ${ }^{[72]}$. 对于实际生产应用, 低浓度催 化剂的使用可以减少催化剂回收过程的投资成本和 生产成本.

不同溶剂中金属卟啉自氧化反应动力学研究表 明, 随着溶剂极性增强, $\mathrm{TPPFeCl}$ 的自氧化速率也增 $大^{[112]}$. 而(TPPFe $)_{2} \mathrm{O}$ 在极性强的溶剂中, 环已醇的产 率反而降低. 这也表明以极性小的氧化底物本身来 做溶剂，可以减少金属卟啉的自氧化速率，增加金属 卟啉的催化效率.

表 5 催化剂浓度对环己烷仿生催化氧化反应的影响 ${ }^{\text {a) }}$

\begin{tabular}{|c|c|c|c|c|}
\hline CoTPP 量(ppm) & 100 & 40 & 8 & 4 \\
\hline 转化率(\%) & 14 & 15 & 19.7 & 20.1 \\
\hline 醇酮选择性(\%) & 69.6 & 75.6 & 78.2 & 81.8 \\
\hline 反应时间(h) ${ }^{b)}$ & 1.0 & 1.5 & 2.0 & 3.0 \\
\hline 催化剂转化数 & 11164 & 33937 & 196410 & 401198 \\
\hline
\end{tabular}

a) $450 \mathrm{~mL}$ 环已烷, $0.6 \mathrm{MPa}$ 空气, $140{ }^{\circ} \mathrm{C}$; b) 达到最大产率

\section{3 非常温条件下金属卟啉仿生催化烃类 C-H 键的空气氧化活化机理}

金属卟啉仿生催化烃类 $\mathrm{C}-\mathrm{H}$ 键氧化活化机理研 究不仅有助于对 CYP450 酶的催化循环的了解, 而且 有助于对其他血红素酶如过氧化物酶、过氧化氢酶的 催化本质的了解 ${ }^{[31]}$. 目前科学家们对于金属卟啉仿 生催化烃类 $\mathrm{C}-\mathrm{H}$ 键氧化活化机理的研究, 主要采用 金属卟啉、能提供原子氧的单充氧化剂和底物作为模 型体系; 研究集中在金属卟啉活性中间体结构、原子 氧进入 $\mathrm{C}-\mathrm{H}$ 键的过程、以及烃类 $\mathrm{C}-\mathrm{H}$ 键氧化活化过 程中金属卟啉-单充氧化剂-底物所构成的循环关系. 这些研究为人们了解金属卟啉仿生催化烃类 $\mathrm{C}-\mathrm{H}$ 键 氧化活化机理提供了大量信息. 在反应中间体研究 方面, 更多科学家认为是具有高活性的高价金属氧 正离子自由基, 它是由单充氧化剂向金属卟 啉的中心金属原子转移一个原子氧所形成. 但该高 价正离子自由基的结构形式是 $\left[\mathrm{PFe}^{\mathrm{IV}}=\mathrm{O}\right]^{+}$还是
$\left[\mathrm{PFe}^{\mathrm{V}}=\mathrm{O}\right]$, 仍然存在争论. 这些结构都通过现代仪器 分析技术和量化计算方法等手段获得了相关信息证

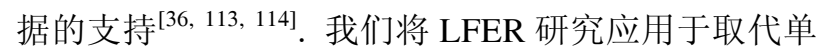
金属卟啉和 $\mu$-氧双金属卟啉仿生催化 PhIO 氧化环己 烷反应, 通过研究反应的 Hammett 关系式发现, 反应 活性中间体为高价金属氧正离子自由基 $\left[\mathrm{PFe}^{\mathrm{IV}}=\mathrm{O}\right]^{+}$. 在原子氧进入 $\mathrm{C}-\mathrm{H}$ 键的过程研究方面, 普遍认为是 高价金属氧正离子自由基从 $\mathrm{C}-\mathrm{H}$ 键提取氢原子的自 由基提取过程, 该过程形成了溶剂笼内的烃基自由 基和高价差基取代金属卟啉. 烃类 $\mathrm{C}-\mathrm{H}$ 键氧化活化 过程中, 金属卟啉-单充氧化剂-底物所构成的循环关 系如图 8 所示.

对于分子氧作为氧化剂的金属卟啉仿生催化烃 类 $\mathrm{C}-\mathrm{H}$ 键氧化活性中间体结构研究, 相对困难更大. 这是由于简单金属卟啉无法在常规条件下实现空气 对烃类 $\mathrm{C}-\mathrm{H}$ 键的氧化活化. 通过 UV-vis ${ }^{[39]},{ }^{1} \mathrm{H}$ $\mathrm{NMR}^{[115]}$ 的在线监测研究和计算机动力学模拟 ${ }^{[16]}$, 研究者提出了金属卟啉仿生催化分子氧氧化烃类 $\mathrm{C}-\mathrm{H}$ 键过程中可能存在亲电性 $\left[\mathrm{PFe}^{\mathrm{IV}}=\mathrm{O}\right]$ 结构 $[39,61,115]$ 和 $\mathrm{PFeO}_{2} \mathrm{H}(\mathrm{R})$ 结构 ${ }^{[90,117]}$. 根据不同的中间体结构, 烃类 $\mathrm{C}-\mathrm{H}$ 键分子氧氧化活化过程中, 金属卟啉-分子 氧-底物所构成的循环关系如图 9 11 所示.

图 9 和 10 所示机理属于仿生催化机理, 而图 11 所示机理则属于碳氢化合物液相氧化中的自由基自 氧化机理. 虽然对于反应中的活性中间体结构还存 在争议, 但都认为反应中存在自由基反应 ${ }^{[2,61,117]}$.

非常温条件下金属卟啉仿生催化烃类 $\mathrm{C}-\mathrm{H}$ 键的 空气氧化反应获得的现象和结果不能通过上述 3 种 机理进行解释. 在非常温条件下, 环己烷 $\mathrm{C}-\mathrm{H}$ 键氧

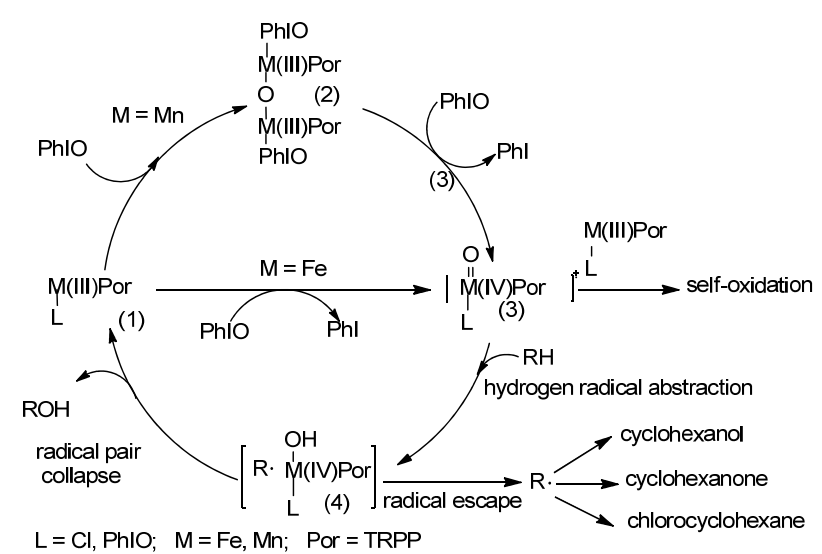

图 8 金属卟啉-单充氧化剂-底物催化过程 


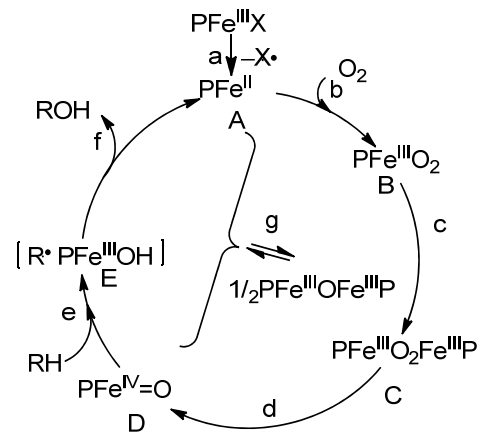

图 9 高价金属氧代物机理(Lyons 等 ${ }^{[61]}$ )

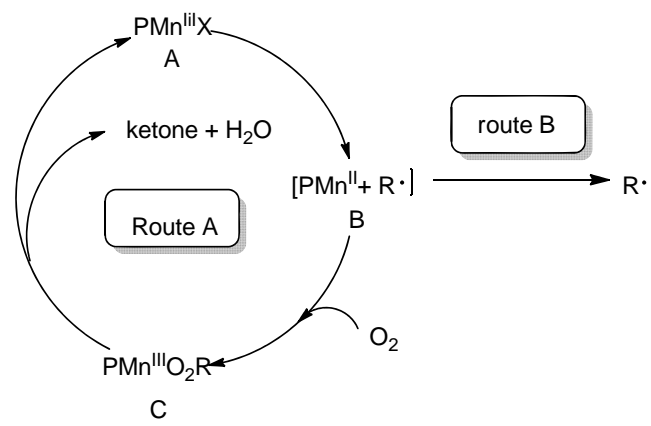

图 10 烷基过氧化过渡金属配合物 $\left(\mathrm{PFe}^{\mathrm{III}} \mathrm{O}_{2} \mathrm{R}\right)$ 机理(Haber 等 ${ }^{[17]}$ )

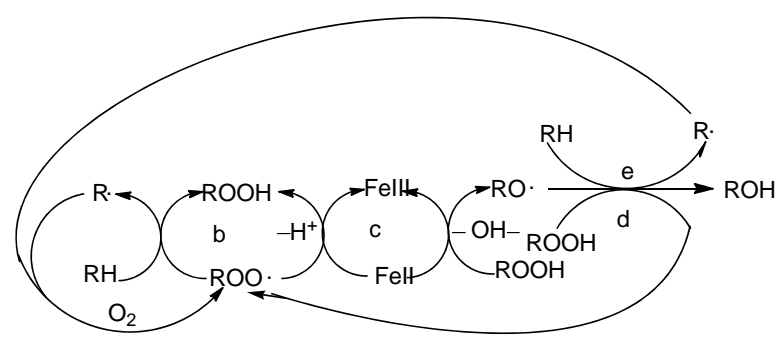

图 11 烃类自由基自氧化机理(Labinger 等 ${ }^{[118]}$ )

化活化的研究表明, 采用浓度仅为 $1 \sim 4 \mathrm{ppm}$ 简单金属 卟啉作为催化剂, 就可以实现环已烷的空气氧

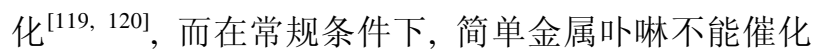
环己烷的空气氧化. 如果在仿生催化的工业条件下, 不使用简单金属卟啉作为催化剂, 环己烷的空气氧 化也不能发生. 尤其是在仿生催化工业条件下, 金属 卟啉催化环己烷 $\mathrm{C}-\mathrm{H}$ 键氧化的催化剂转化数高达 400000 以上, 反应在 $45 \mathrm{~min}$ 左右就可完成, 催化剂 的效率远高于传统均相催化反应. 上述现象表明, 仿 生催化工业条件下金属卟啉仿生催化烃类 $\mathrm{C}-\mathrm{H}$ 键的
空气氧化活化机理不能简单套用文献已经报道的常 规条件下的反应机理，也不能套用非仿生催化工业 条件下的烃类 $\mathrm{C}-\mathrm{H}$ 键的空气氧化活化机理.

由于常规的现代分析仪器和技术不能在工业条 件下使用，因此，工业条件下金属卟啉仿生催化烃类 $\mathrm{C}-\mathrm{H}$ 键的空气氧化活化机理, 还很难使用现代分析 仪器进行在线研究.

理论和计算化学模拟用于工业条件下金属卟啉 仿生催化烃类 $\mathrm{C}-\mathrm{H}$ 键的空气氧化活化机理研究已经 获得一些新的信息. 对钴卟啉催化分子氧活化模型 的理论计算结果表明, 分子氧中的一个氧原子端基 连接到钴原子为能量最优化结构(图 12(a), 而不是文 献 ${ }^{[121]}$ 报道的氧原子两侧连接铁卟啉(图 12(b)). 催化

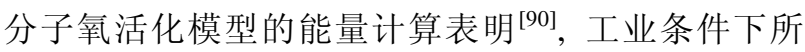
进行的铁卟啉仿生催化分子氧活化过程中, 铁卟啉 环上的电子进入金属原子的 $\mathrm{d}$ 轨道, 然后转移到分子 氧. 卟啉环上的吸电子取代基能降低铁卟啉的 $E_{\mathrm{LUMO}-\mathrm{b}}$, 加速电子从铁卟啉到分子氧的转移, 有利于 分子氧的活化而增加铁卟啉的催化活性. 9 种铁卟啉 $E_{\mathrm{LUMO}-\mathrm{b}}$ 概率密度图表明, 铁卟啉的 LUMO 轨道由卟 啉环和取代苯基的原子轨道以及铁原子的 $3 \mathrm{~d}$ 轨道组 成, 中位苯环上不同取代基对卟啉环的电子具有重 要影响(图 13).

此外，第二代金属卟啉和第三代金属卟啉与未 取代的四苯基金属卟啉催化活性上的差别至少在一 定程度上还可以归因于活性金属卟啉的金属中心亲

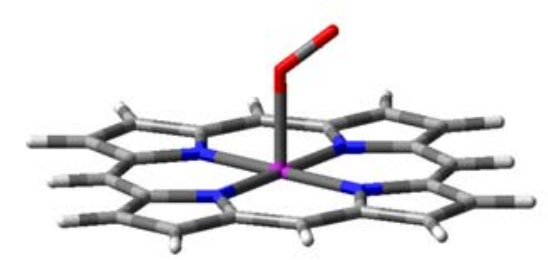

(a) 端基连接中间体

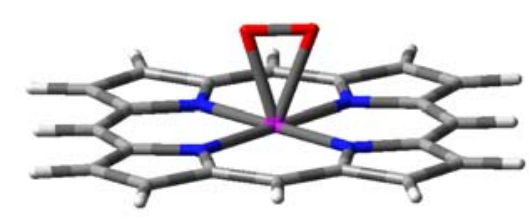

(b) 侧基连接中间体

图 12 钴卟啉催化分子氧活化模型 

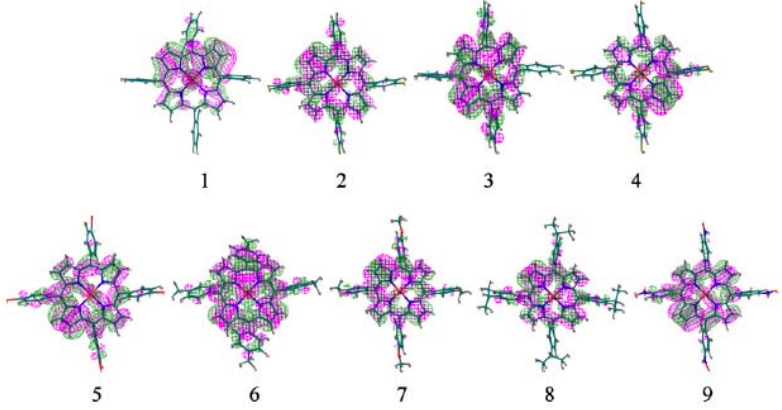

图 139 种铁卟啉 $E_{\mathrm{LUMO}-\mathrm{b}}$ 概率密度

电性增加. 因为吸电子取代基可降低高价金属氧代 物 $\mathrm{a}_{2 \mathrm{u}}$ 的分子轨道能, 亲电性增强, 它们比相应的未 取代的四苯基金属卟啉具有更强的氧化能力 ${ }^{[122,123]}$.

在自由基自氧化体系中, 分子氧氧化环己烷产 物环己酮和环己醇比一般小于 $2^{[124 ~ 130]}$. 本课题组在 工业条件下使用分子氧进行的金属卟啉仿生催化环 己烷 $\mathrm{C}-\mathrm{H}$ 键氧化研究发现, 环己酮和环己醇比最终 都维持在 1 左右(表 6) ${ }^{[72]}$. 这表明工业条件下的金属 卟啉催化环已烷 $\mathrm{C}-\mathrm{H}$ 键氧化的反应仍然具有自由基 自氧化反应的特征.

表 6 空气作氧化剂时温度对产物酮含量(\%)的影响 ${ }^{\mathrm{a})}$

\begin{tabular}{cccc}
\hline 反应温度 $\left({ }^{\circ} \mathrm{C}\right)$ & 120 & 130 & 140 \\
转化率 $(\%)$ & 8.0 & 14.6 & 15.0 \\
醇酔选择性 $(\%)$ & 62.6 & 65.7 & 75.6 \\
醇酮比 & 1.04 & 0.86 & 0.91 \\
反应时间 $(\mathrm{h}){ }^{\mathrm{b})}$ & 5.5 & 2.5 & 1.5 \\
催化剂转化数 & 16518 & 31600 & 33937 \\
\hline
\end{tabular}

a) $450 \mathrm{~mL}$ 环已烷, $40 \mathrm{ppm}$ CoTPP, $0.6 \mathrm{MPa}$ 空气, $140{ }^{\circ} \mathrm{C}$; b) 达到最大产率
金属卟啉-氧化剂-底物模型获得的烃类 $\mathrm{C}-\mathrm{H}$ 键 氧化活化循环关系不能解释工业条件下的酮产物的 形成, 而且碳氢化合物液相氧化中的自由基自氧化 机理无法解释金属卟啉催化剂存在的作用. 我们分 别在空气和氮气环境下以金属卟啉催化 PhIO 分别氧 化环己烷和环己醇的反应作为对象，研究了环己烷 氧化产物环己醇和环己酮的竞争反应动力学以及环 己醇氧化反应，获得了产物酮的产生途径 ${ }^{[131]}$. 我们 提出了非常温条件下金属卟啉仿生催化循环和烃类 自由基氧化循环相偶联的烃类 $\mathrm{C}-\mathrm{H}$ 键氧化活化途径 (图 14) ${ }^{[45,120]}$. 产物环己醇来源于生物氧化循环过程 (图 14 中(1) $\rightarrow(8)$ )中的笼内自由基碰撞产物, 而环己 酮是从溶剂笼逃逸出来的烷基自由基按照化学循环 过程(图 14 中(9) $\rightarrow(11)$ )与空气反应的产物(图 14 中 (11)). 进一步研究发现, 当温度增加或者体系黏度减 小时, 有利于自由基的逃逸, 增加酮的产物(图 14 中 $(7) \rightarrow(9))$.

\section{4 金属卟啉仿生催化氧化的应用}

\section{1 对不同烃类 $\mathbf{C}-\mathbf{H}$ 键的催化氧化活化}

碳氢化合物的选择性 $\mathrm{C}-\mathrm{H}$ 氧化活化是一个挑战 性的课题 ${ }^{[132]}$, 但具有巨大的学术和工业价值. 早在 20 世纪 80 年代, 已经发现了金属卟啉能催化 PhIO 对 烷烃分子中惰性 $\mathrm{sp}^{3} \mathrm{C}-\mathrm{H}$ 键的温和氧化. 在有不同 $\mathrm{C}-\mathrm{H}$ 键的的情况下, 氧化产物为 $3^{\circ}$ 和 $2^{\circ} \mathrm{C}-\mathrm{H}$ 键的氧 化产物 ${ }^{[133]}$. 在合适的条件下, 金属卟啉还能催化空 气氧化环己烷 ${ }^{[72,77,78,92,99,134]}$ 和甲基环已烷 $\mathrm{C}-\mathrm{H}$ 键的 氧化 ${ }^{[87,135,136]}$, 氧化产物主要是 $3^{\circ}$ 和 $2^{\circ} \mathrm{C}-\mathrm{H}$ 键氧化
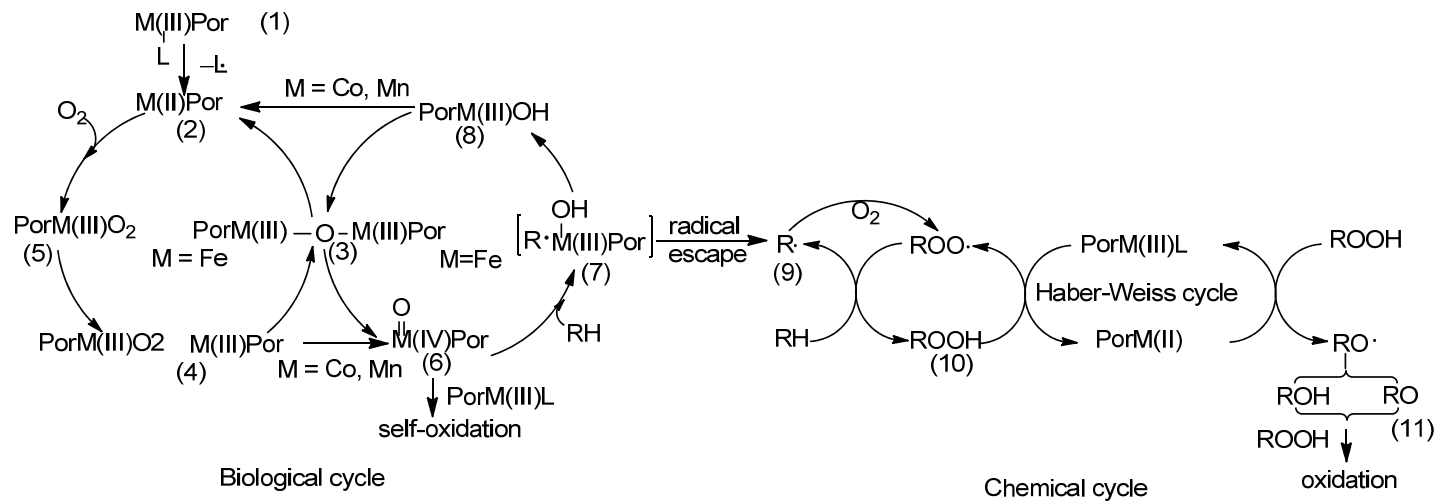

图 14 金属卟啉仿生催化循环和烃类自由基自氧化循环相偶联反应过程 
产物, 如式(5)和(6). 随着时间延长, 环己烷C-C键断 裂的产物已二酸也开始增加 ${ }^{[137,138]}$, 如式(7).

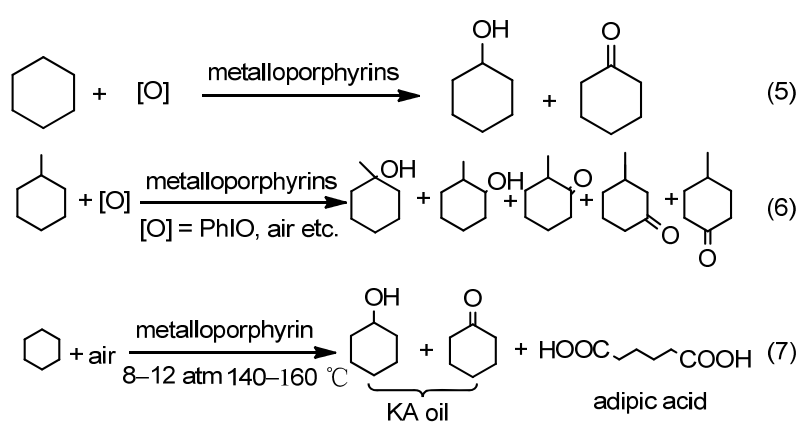

通过控制反应条件, 环己烷的氧化能够控制在 环已酮或者己二酸作为主要产物. 甲基环已烷的氧 化产物甲基环己酮没有环己酮的不愉快气味并比环 己酮的毒性更低, 有可能替代环已酮作为工业溶剂.

2-甲基丁烷和甲基环已烷同时含有 3 种不同的惰 性 $\mathrm{sp}^{3} \mathrm{C}-\mathrm{H}$ 键, 它们的氧化可以得到不同的氧化产物, 如式(6)和(8). 乙酰葡萄糖氧代苯基铁和锰卟啉对 2甲荃丁烷中 $1^{\circ} \mathrm{C}-\mathrm{H}$ 键表现出专一催化活化作用, 其 他取代的铁、锰卟啉对 $3^{\circ} \mathrm{C}-\mathrm{H}$ 键的氧化选择性较好, 但带有强给电子基的铁卟啉(如 $\mathrm{T}_{\mathrm{p}-\mathrm{OH}} \mathrm{PPFeCl}$ )和高位 阻的镇吓啉 (如 $\mathrm{T}_{\mathrm{p}-(i-\mathrm{Pr})} \mathrm{PPMnCl}$ )对 $2^{\circ} \mathrm{C}-\mathrm{H}$ 键的氧化选 择性较好 ${ }^{[139,140]}$, 而镧系金属卟啉催化 $\mathrm{PhIO}$ 甲基环 己烷时, 对 $2^{\circ} \mathrm{C}-\mathrm{H}$ 键表现出专一催化活化作用 ${ }^{[141]}$.

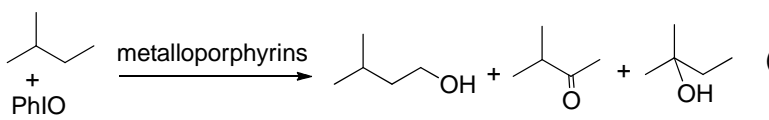

金属卟啉催化烯烃氧化时存在 $\mathrm{sp}^{3} \mathrm{C}-\mathrm{H}$ 键羊基化 和 $\mathrm{sp}^{2} \mathrm{C}=\mathrm{C}$ 键环氧化的竞争. 在金属卟啉- $\mathrm{O}_{2}$-烷烃-还 原剂体系, 烯烃主要发生 $\mathrm{sp}^{2} \mathrm{C}=\mathrm{C}$ 键的环氧化 ${ }^{[36,142]}$, 而金属卟啉催化分子氧直接氧化烯烃主要得到 $\mathrm{sp}^{3} \mathrm{C}-\mathrm{H}$ 键羟基化产物 ${ }^{[36,143]}$, 难以发生环氧化. 通过 研究简单单金属卟啉和双金属卟啉在常压和高压下 仿生催化环己烯空气氧化发现, 环己烯氧化发生在 $\mathrm{sp}^{3} \mathrm{C}-\mathrm{H}$ 键, 主要得到环已烯酮, 选择性达到近 75\%, 如式(9) ${ }^{[144]}$. 而简单金属卟啉仿生催化空气氧化 $\alpha$-蒎 烯得到比较多的环氧化产物 (I, II), 同时还产生了 少量烯丙位 $\mathrm{sp}^{3} \mathrm{C}-\mathrm{H}$ 键的氧化产物 (III, IV, V), 没 有 $1^{\circ} \mathrm{C}-\mathrm{H}$ 和 $2^{\circ} \mathrm{C}-\mathrm{H}$ 键氧化产物, 如式 $(10)^{[145]}$. 单铁 和单锰卟啉仿生催化空气氧化 $\alpha$-蒎烯反应中的取代 基效应研究结果表明 ${ }^{[146]}$, 反应速率常数 $\mathrm{K}$ 与取代基
常数之间符合 Hammett 关系, $\rho$ 全为正值, 数值分别 为 0.62 和 1.22 .
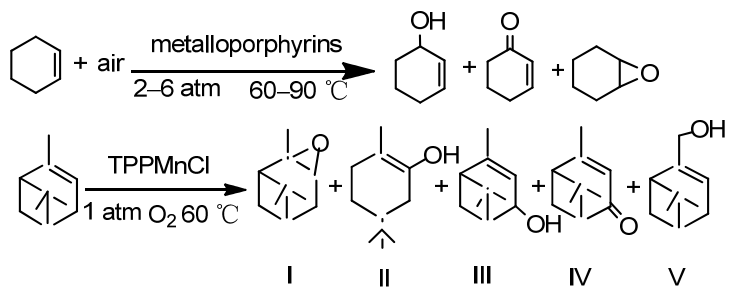

金属卟啉仿生催化氧化芳烃可生成茮基 $\mathrm{sp}^{3} \mathrm{C}-\mathrm{H}$ 键氧 化产物和 $\mathrm{sp}^{2} \mathrm{C}-\mathrm{H}$ 的苯环羟基化产物, 氧化产物主要 依赖于反应条件(催化剂、氧化剂和溶剂等) ${ }^{[147]}$. 苄基 $\mathrm{sp}^{3} \mathrm{C}-\mathrm{H}$ 键的氧化容易在分子氧条件完成. 通过对简

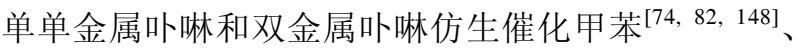
乙苯 ${ }^{[81]}$ 和对二甲苯 $\left.{ }^{[149}, 150\right]$ 空气氧化的研究发现, ppm 浓度的钴卟啉在 $160{ }^{\circ} \mathrm{C}$ 和 $0.8 \mathrm{MPa}$ 下，即可催化空气 氧化甲苯 $\mathrm{sp}^{3} \mathrm{C}-\mathrm{H}$ 键成苯甲醛、苯甲醇和苯甲酸(式(9)), 而相同条件下只对对二甲苯的一个 $\mathrm{sp}^{3} \mathrm{C}-\mathrm{H}$ 键的氧化 催化作用 ${ }^{[149]}$. 为了使对二甲苯的两个 $\mathrm{sp}^{3} \mathrm{C}-\mathrm{H}$ 键发生 氧化, 还需加入醋酸钴辅助催化(式(11) $)^{[150]}$. 以 $\mathrm{ppm}$ 浓度的锰卟啉和醋酸钴作催化剂, 在 $180{ }^{\circ} \mathrm{C}$ 和 2.0 $\mathrm{MPa}$ 压力下, 对二甲苯转化率达 $67 \%$, 对苯二甲酸的 选择性达 17\%(式(12)).

由于羧基的引入，对甲基苯甲酸难以进一步氧 化成对苯二甲酸. 金属卟啉和醋酸钴复合催化下能 实现对甲基苯甲酸 $\mathrm{sp}^{3} \mathrm{C}-\mathrm{H}$ 键的氧化(式(13)). 对甲基 苯甲酸的转化率达 $62.9 \%$, 对苯二甲酸的选择性达 $96.8 \%^{[151]}$

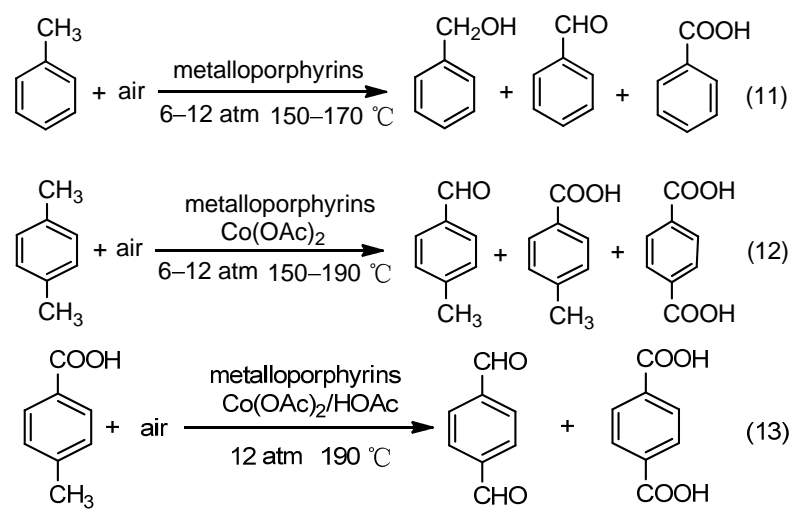

\section{2 金属卟啉仿生催化烃类 $\mathbf{C}-\mathrm{H}$ 键氧化活化的工} 业应用

烃类催化氧化是基本的石油化工工艺之一，通 过化学催化生产的有机化学品中, 烃类催化氧化生 
产的产品约占 $25 \%$. 但目前碳氢化合物的选择性催 化氧化还刚刚起步. 本课题组根据碳氢化合物仿生 催化氧化特点, 设计并研制了如图所示的仿生催化 烃类 $\mathrm{C}-\mathrm{H}$ 键氧化活化的三釜串联工业模式装置(图 15)。通过调节反应温度和停留时间, 该装置可以在 3 个反应釜中分别发生以生物催化或者化学催化为主 的过程, 从而达到控制氧化产物选择性的效果. 通过 该模式装置, 我们对国际市场上需求量巨大的环己 酮、苯甲醛和己二酸, 系统地研究了每一种产物所对 应的优化反应条件 ${ }^{[72,119,137,148]}$. 例如反应温度、体系 中的空气浓度和压力, 催化剂种类和浓度、反应时间 等; 结合金属卟啉催化剂的特性以及反应过程动力 学分析, 形成了可工业化应用的金属卟啉仿生催化 氧化技术，该技术的特点是，对不同碳氢化合物的氧 化, 可通过选择合适的反应温度使生物催化循环产 生的烃类自由基逃出溶剂笼, 进一步发生化学催化 循环. 该过程模拟生命过程中细胞色素 P-450 酶催化 氧气氧化碳氢化合物的过程, 只需使用 $\mathrm{ppm}$ 浓度的 简单金属卟啉催化剂, 催化剂不需要回收, 也不污染 产物; 以空气为氧化剂; 不需要使用酸碱介质、添加 剂和溶剂. 与目前工业上使用的化学催化和生物催 化工艺相比, 该工艺大为简化, 环境友好, 反应转化 率和产物选择性得到提高.

\subsection{1 金属卟啉仿生催化环己烷氧化合成 KA 油}

环己酮是生产己内酰胺和己二酸的基本原料, 我国自给率 $50 \%$. 国际上 $90 \%$ 以上的环已酮是在高 温高压下直接用空气将环已烷氧化产生过氧化物, 过氧化物在碱性条件下分解、然后脱氢产生环己酮.

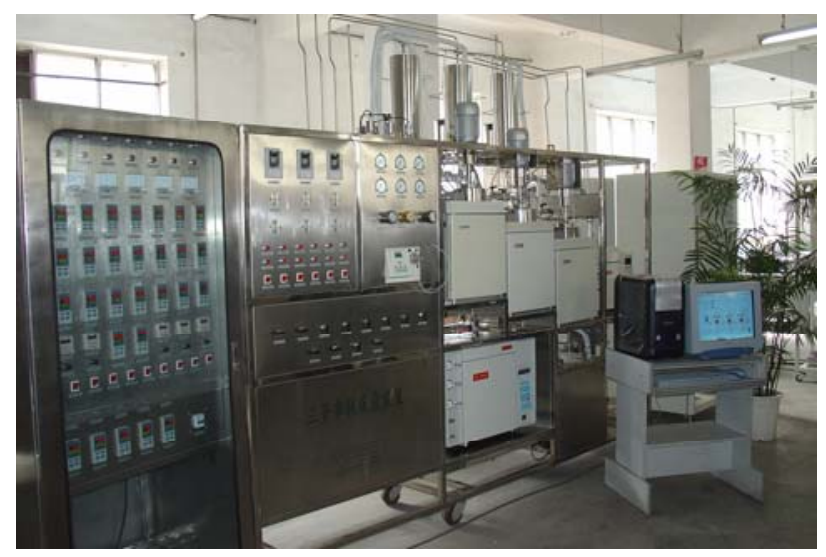

图 15 仿生催化烃类 C-H 键氧化活化的工业模式装置
目前 国际上最先进的环己烷氧化生产环己酮工艺, 环己烷一般只有 $4 \%$ \% \% 的转化率, $78 \%$ 的选择性 ${ }^{[5]}$, 同时, 环己烷氧化产物过氧化物需要分解才能生产 出环已酮, 该过程需要大量使用碱液, 三废处理费用 大. 因此, 该工艺被公认为全球大型化工产品生产中 效率最低的工艺, 是困绕国际己内酰胺生产企业近 40 年的难题 ${ }^{152]}$.

我们将金属卟啉仿生催化技术引入环己烷空气 氧化过程研发了金属卟啉仿生催化环已烷空气氧化 制备环已酮技术 ${ }^{[153,154]}$, 该技术能同时提高环己烷反 应转化率和环已酮选择性.

2003 年, 仿生催化制备环己酮技术在 800 吨/年 三釜串联流程中试装置上进行了连续试验, 催化剂 浓度 $3 \mathrm{ppm}$, 环已烷转化率大于 $8 \%$, 环已酮选择性达 到 90\%. 2004 年中国石化总公司巴陵分公司在引进 的荷兰 DSM 公司 4.5 万吨和 7 万吨环已酮装置上对 金属卟啉仿生催化环已烷空气氧化制备环己酮技术 进行工业试验, 在国际上率先实现了烃类仿生催化 氧化从实验室研究进入工业应用的突破 ${ }^{[120]}$. 工业试 验结果表明, 该技术通过加入 $2 \mathrm{ppm}$ 金属卟啉到环己 烷中, 反应温度可降低 $20{ }^{\circ} \mathrm{C}$, 反应压力降低 $4 \mathrm{~kg}$, 而反应转化率提高到 $7.1 \%$, 环已酮选择性提高到 $87 \%$, 环已酮设备生产能力提高 1 倍, 生产成本降低 $15 \%$, 三废排放减少 $60 \%$. 同时，该工艺中无催化剂 回收问题.

\subsection{2 金属卟啉仿生催化环己烷氧化合成 KA 油和 已二酸}

己二酸最大的消费领域是聚氨酯、尼龙 66 盐和 增塑剂. 2010 年我国需求已超过 80 万吨, 而我国产量 不到 40 万吨. 目前国际工业上 $93 \%$ 的已二酸来自环 己酮的 $\mathrm{HNO}_{3}$ 氧化. 该方法以铜和钒盐作催化剂, 在 $330 \sim 353 \mathrm{~K}, 0.1 \sim 0.4 \mathrm{MPa}$ 条件下, 采用 50\% 60\%硝酸 氧化生成己二酸, 经结晶、增浓、离心分离得到精己 二酸. 该过程中产生大量的氮氧化物 $\left(\mathrm{N}_{2} \mathrm{O}\right)$ 尾气, 对 环境造成极大污染 ${ }^{[155]}$. 同时, 由于氧化反应使用 $50 \%$ 60\%硝酸, 腐蚀设备且产生大量酸性废水, 每 生产 1 吨已二酸约产生 19 吨酸性废水.

本课题组将金属吓啉仿生催化技术引入环己烷 空气氧化过程开发出了金属卟啉仿生催化环己烷空 气氧化联产环已酮和已二酸技术 ${ }^{[156 ~ 158]}$, 该技术原料 
只有环己烷和空气, 在 $5 \mathrm{ppm}$ 金属卟㕲作用下, 空气 氧化环己烷成为己二酸. 环己烷的转化率可达 $14 \%$, 环己酮和已二酸总收率可以达到 $90 \%$ 以上, 环已酮 和己二酸的比例可以通过改变工艺条件和催化剂类 型进行调整. 该工艺避免了使用硝酸带来的破坏环 境的问题, 也避免了硝酸对设备的腐蚀. 因此, 仿生 催化环己烷空气氧化联产环己酮和己二酸技术是一 个绿色环保技术. 目前, 国际上还没有开发成功可工 业化应用的环已烷空气氧化制备已二酸技术.

\subsection{3 金属卟啉仿生催化甲苯氧化合成苯甲醛和苯 甲醇}

苯甲醛和苯甲醇是广泛用于医药、香精香料、染 料、农用化学品等领域重要的化工原料. 工业上苯甲 醛与苯甲醇主要先经甲苯氯化再经过酸性或碱性水 解制得 ${ }^{[159]}$. 在此合成方法中, $\mathrm{Cl}_{2}$ 为液态使操作难以 控制, 同时在水解过程中产生大量的污染物, 如 $\mathrm{HCl}$ 气体及重金属盐类. 更为严重的是, 这种方法生产的 苯甲醛与苯甲醇由于含有含卤化合物使其纯度不高, 不能应用于食品、医药、化妆品等工业, 从而严重制 约了其应用范围. 目前, 无氯苯甲醛只能来源于甲苯 空气氧化制苯甲酸的副产物回收(占苯甲酸的 $1 \% \sim 2 \%)^{[160]}$.

我们将金属卟啉仿生催化技术引入甲苯空气氧 化过程发明了金属卟啉仿生催化甲苯空气氧化制备 苯甲醛和苯甲醇技术 ${ }^{[74,161,162]}$, 该技术原料只有甲苯 和空气, 在 $2 \mathrm{ppm}$ 金属卟啉作用下, 空气氧化甲苯成 为苯甲醛和苯甲醇, 副产物是苯甲酸. 在转化率为 $10 \%$ 时, 醛醇收率超过 $50 \%$, 苯甲醛、苯甲醇和苯甲 酸的比例可以通过改变工艺条件和催化剂类型进行 调整.

\section{5 展望}

金属卟啉模拟细胞色素 P450 酶仿生催化氧化活 化烃类 $\mathrm{C}-\mathrm{H}$ 键的方法只需使用 $\mathrm{ppm}$ 浓度的简单金属 卟啉催化剂, 以空气为氧化剂, 不需要使用酸碱介 质、添加剂和溶剂, 催化剂不需要回收, 也不污染产 物, 是一种碳氢化合物高效氧化的绿色工艺, 适合大 工业碳氢化合物氧化生产. 与目前工业上使用的化 学催化和生物催化工艺相比, 该工艺大为简化, 环境 友好, 反应转化率和产物选择性得到提高, 是目前大 宗碳氢化合物氧化制备含氧有机化学品最有前途的 催化氧化方法之一. 通过选择合适的金属卟㕲结构 和反应条件可以实现对不同烃类 $\mathrm{C}-\mathrm{H}$ 键选择性的氧 化活化.

由于烃类 $\mathrm{C}-\mathrm{H}$ 键仿生催化氧化活化方法所经历 的过程不同于传统的化学催化或者生物催化, 在烃 类 $\mathrm{C}-\mathrm{H}$ 键仿生催化氧化活化研究过程中需要对现有 化学催化和生物催化的理论进一步完善. 由于受反 应条件的制约, 目前的很多仪器设备和研究方法在 用于烃类 $\mathrm{C}-\mathrm{H}$ 键仿生催化氧化活化研究时存在局限 性. 物理有机化学研究原理和方法, 尤其是量子化学 计算和分子模拟方法优化计算在烃类 $\mathrm{C}-\mathrm{H}$ 键仿生催 化氧化活化研究中可以发挥重要作用. 烃类仿生催 化氧化过程中 $\mathrm{C}-\mathrm{H}$ 键和分子氧的活化过程, 金属卟 啉的作用机制以及涉及的中间体结构、分子氧与 $\mathrm{C}-\mathrm{H}$ 键活化过程的联系与耦合仍然是烃类 $\mathrm{C}-\mathrm{H}$ 键仿生催 化氧化活化研究的挑战问题. 上述基础研究的进展 将丰富金属卟啉仿生催化碳氢化合物理论并为获得 良好转化率及产物选择性的碳氢化合物绿色氧化工 艺提供理论依据.

\section{参考文献}

1 Bäckvall J-E. Modern Oxidation Methods. New York: Wiley-VCH, 2010

2 Olah GA, Molnár Á. Hydrocarbon Chemistry. New York: Wiley-VCH, 2003

3 Shilov AE, Shul'pin GB. Activation and Catalytic Reactions of Saturated Hydrocarbons in the Presence of Metal Complexes. Boston: Springer-Verlag, 2000

4 Sheldon RA, Kochi JA. Metal-Catalyzed Oxidations of Organic Compounds. New York: Academic Press, 1981

5 Suresh AK, Sharma MM, Sridhar T. Engineering aspects of industrial liquid-phase air oxidation of hydrocarbon. Ind Eng Chem Res, 2000,

1410 
39: $3958-3997$

6 Punniyamurthy T, Velusamy S, Iqbal J. Recent advances in transition metal catalyzed oxidation of organic substrates with molecular oxygen. Chem Rev, 2005, 105(6): 2329-2363

7 Ueda W. Challenges in alkane activation and selective oxidation. Catal Today, 2001, 71: 1-1

8 Schuchardt U, Cardoso D, Sercheli R, Pereira R, da Cruz RS, Guerreiro MC, Mandelli D, Spinacé EV, Pires EL. Cyclohexane oxidation continues to be a challenge. Appl Catal A: Gen, 2001, 211: 1-17

9 Sheldon RA, Arends I, Hanefeld U. Green Chemistry and Catalysis. New York: Wiley-VCH, 2007

10 Clark JH, Macquarrie DJ. Handbook of Green Chemistry and Technology. New York: Wiley-VCH, 2002

11 Cavani F. Catalytic selective oxidation: The forefront in the challenge for a more sustainable chemical industry. Catal Today, 2010, 157: $8-15$

12 Hermans I, Spier ES. Neuenschwander U, Turra N, Baiker A. Selective oxidation catalysis: Opportunities and challenges. Top Catal, 2009, 52: $1162-1174$

13 Thomas JM, Raja R, Sankar G, Bell RG. Molecular sieve catalysts for the regioselective and shape selective oxyfunctionalization of alkanes in air. Acc Chem Res, 2001, 34(3): 191-200

14 Pina CD, Falletta E, Prati L, Rossi M. Selective oxidation using gold. Chem Soc Rev, 2008, 37: 2077-2095

15 Sono M, Roach MP, Coulter ED, Dawson JH. Heme-containing oxygenases. Chem Rev, 1996, 96(7): 2841-2888

16 Momenteau M, Reed CA. Synthetic heme-dioxygen complexes. Chem Rev, 1994, 94(3): 659-698

17 Shilov AE. Metal Complexes in Biomimetic Chemical Reactions: $N_{2}$ Fixation in Solution, Activation and Oxidation of Alkanes, Chemical Models of Photosynthesis. Boca Raton: CRC Press, 1997

18 Crossland JL, Tyler DR. Iron-dinitrogen coordination chemistry: Dinitrogen activation and reactivity. Coord Chem Rev, 2010, (254): 1883-1894

19 Fryzuk MD, Johnson SA. The continuing story of dinitrogen activation. Coord Chem Rev, 2000, (200-202): 379-409

20 张纯喜. 固氮酶的固氮机理和其人工模拟问题的探讨. 化学进展, 1997, 9(2): 131-139

21 Magnuson A, Anderlund M, Johansson O, Lindblad P, Lomoth R, Polivka T, Ott S, Stensjo K, Styring S, Sundstrom V. Biomimetic and microbial approaches to solar fuel generation. Acc Chem Res, 2009, 42(12): 1899-1909

22 Gust D, Moore TA, Moore AL. Solar fuels via artificial photosynthesis. Acc Chem Res, 2009, 42(12): 1890-1898

23 李晓慧, 范同祥. 人工光合作用. 化学进展, 2011, 23(9): 1841-1853

24 江国防, 田波, 郭灿城. 仿生催化及其在烃类氧化中的应用. 大学化学, 2011, 26(2): 1-5

25 Makris T, Denisov I, Schlichting I, Sligar S. Activation of molecular oxygen by cytochrome P450. In: Ortiz de Montellano PR, Ed. Cytochrome P450: Structure, Mechanism, and Biochemistry, New York: Kluwer Academic Publishers, 2005, 149-182

26 Julsing MK, Cornelissen S, Bühler B, Schmid A. Heme-iron oxygenases: Powerful industrial biocatalysts? Curr Opin Chem Biol, 2008, 12(2): $177-186$

27 Groves JT, Nemo TE, Myers RS. Hydroxylation and epoxidation catalyzed by iron-porphine complexes. Oxygen transfer from iodosylbenzene. J Am Chem Soc, 1979, 101: 1032-1033

28 Meunier B. Metalloporphyrins as versatile catalysts for oxidation reactions and oxidative DNA cleavage. Chem Rev, 1992, 92(6): 1411-1456

29 Costas M. Selective X-H oxidation catalyzed by metalloporphyrins. Coord Chem Rev, 2011, 255: 2912-2932

30 Che C-M, Huang J-S. Metalloporphyrin-based oxidation systems: From biomimetic reactions to application in organic synthesis. Chem Commun, 2009, 3996-4015

31 Mansuy D. A brief history of the contribution of metalloporphyrin models to cytochrome P450 chemistry and oxidation catalysis. C R Chim, 2007, 10(4-5): 392-413

32 Woggon WD. Metalloporphyrines as active site analogues lessons from enzymes and enzyme models. Acc Chem Res, 2005, 38(2): 127-136

33 Meunier B, de Visser SP, Shaik S. Mechanism of oxidation reactions catalyzed by cytochrome P450 enzymes. Chem Rev, 2004, 104(9): 3947-3980

34 Rose E, Andrioletti B, Zrig S, Quelquejeu-Ehteve M. Enantioselective epoxidation of olefins with chiral metalloporphyrin catalysts. Chem Soc Rev, 2005, 34: 573-583

35 Ji LN, Peng XB, Huang JW. Progress in study on metalloporphyrin mimicking metalloenzymes. Prog Nat Sci, 2002, 12(5): 321-330

36 Meunier B, Robert A, Pratviel G, Bernadou J. Metalloporphyrins in catalytic oxidations and oxidative DNA cleavage. In: Kadish KM, Smith KM, Guilard R, Eds. Porphyrin Handbook. vol 4. Biochemistry and Binding: Activation of Small Moleculars. New York: Academic 
Press, 2000, 119-187

37 Mlodnicka T. Metalloporphyrins as catalysts in autoxidation process: A review. J Mol Catal A: Chem, 1986, 36: 205-242

38 Mansuy D. Activation of alkanes: The biomimetic approach. Coord Chem Rev, 1993, 125(1-2): 129-141

39 Ellis PE, Lyons JE. Selective air oxidation of light alkanes catalyzed by activated metalloporphyrins-the search for a suprabiotic system. Coord Chem Rev, 1990, 105(2): 181-193

40 Dolphin D, Traylor TG, Xie LY. Polyhaloporphyrins: unusual ligands for metals and metal-catalyzed oxidation. Acc Chem Res, 1997, 30 : 251-259

41 Haber J, Matachowski L, Pamin K, Połtowicz J. Manganese porphyrins as catalysts for oxidation of cyclooctane in Lyons system. $J$ Mol Catal A: Chem, 2000, 162: 105-109

42 Evans S, Lindsay Smith JR. The oxidation of ethylbenzene and other alkylaromatics by dioxygen catalysed by iron(III) tetrakis(pentafluorophenyl)porphyrin and related iron porphyrins. J Chem Soc Perkin Trans 2, 2000, 1541-1551

43 王兰芝, 余远斌, 徐未未, 张燕慧, 纪红兵. 金属卟啉类模拟酶催化剂研究. 化学进展, 2005, 17(4): 678-685

44 周贤太, 纪红兵, 裴丽霞, 余远斌, 徐建昌, 王乐夫. 金属卟啉催化剂应用于均相氧化反应的研究进展. 有机化学, 2007, 27(9): 1039-1049

45 Jiang GF, Liu Q, Guo CC. Biomimetic oxidation of hydrocarbons with air over metalloporphyrins. In: George A, Ed. Biomimetic Based Applications. InTech, 2011, 31-58

46 Lindsey JS. Synthetic routes to meso-patterned porphyrins. Acc Chem Res, 2010, 43(2): 300-311

47 Sanders JKM, Bampos N, Clyde-Watson ZE, Darling SL, Hawley JC, Kim H-J, Mak CC, Webb SJ. Axial coordination chemistry of metalloporphyrins. In: Kadish K M, Smith K M, Guilard R, Eds. Porphyrin Handbook. vol 3. Inorganic, Organometallic and Coordination Chemistry. New York: Academic Press, 2000, 1-48

48 Kurtz Jr DM. Oxo- and hydroxo-bridged diiron complexes: A chemical perspective on a biological unit. Chem Rev, 1990, 90 (4): 585-606

49 Ji LN, Liu M, Hsieh AK. Syntheses and characterization of some porphyrins and metalloporphyrins. Inorg Chim Acta, 1990, 178: 59-65

50 Socoteanu RP, Ion RM, Licsandru D, Ureche-Fotea A. Studies on porphyrin $\mu$-oxo-dimers. Synthesis, spectral characterization and catalytic applications of metalloporphyrin $\mu$-oxo-dimers. Prog Catal, 2000, 9(1-2): 57-64

51 Kumar A, Maji S, Dubey P, Abhilash GJ, Pandey S, Sarkar S. One-pot general synthesis of metalloporphyrins. Tetrahedron Lett, 2007, 48: 7287-7290

52 Sharma RK, Ahuja G, Sidhwani IT. A new one pot and solvent-free synthesis of nickel porphyrin complex. Green Chem Lett Rev, 2009, 2(2): 101-105

53 Mirafzal GA, Bosse HM, Summer JM. An efficient method for the synthesis of manganese(III) meso-tetraaryl-porphyrins. Tetrahedron Lett, 1999, 40: 623-626

54 李忠芳, 王素文, 王纪孝, 王亚权, 王宇新. 过渡金属离子为模板的卟啉过渡金属配合物的合成研究. 无机化学学报, 2003, 19(7): 691-698

55 郭灿城, 刘强, 公衍之. 一种金属卟啉的合成方法. CN 200310110537.5, 2006-01-25

56 Liu Q, Gong YZ, Gong CJ, Li QH, Guo CC. A new one-pot synthesis of $\mu$-oxo dimeric iron(III) porphyrins from meso-tetraarylporphyrins. J Porphyr Phthalocy, 2009, 13: 854-858

57 郭灿城, 罗伟平, 陈铁桥, 刘强. 四芳基卟啉的合成方法与设备. CN 200910043414.1, 2011-06-15

58 Quici S, Banfi S, Pozzi G. Simple synthetic models of cytochrome P-450: Efficient catalysts in hydrocarbon oxidations. Gazz Chim Ital, 1993, 123: 597-612

59 Serra AC, Marçalo EC, Rocha Gonsalves AMd'A. A view on the mechanism of metalloporphyrin degradation in hydrogen peroxide epoxidation reactions. J Mol Catal A: Chem, 2004, 215: 17-21

60 Labinger JA, Bercaw JE. Understanding and exploiting C-H bond activation. Nature, 2002, 417: 507-514

61 Lyons JE, Ellis PE Jr, Myers HK Jr. Halogenated metalloporphyrin complexes as catalysts for selective reactions of acyclic alkane with molecular oxygen. J Catal, 1995, 155: 59-73

62 Bugg TDH. Dioxygenase enzymes: Catalytic mechanisms and chemical modelscatalytic mechanisms and chemical models. Tetrahedron, 2003, 59: 7075-7101

63 Schlichting I, Berendzen J, Chu K, Stock AM, Maves SA, Benson DE, Sweet RM, Ringe D, Petsko GA, Sligar SG. The catalytic pathway of cytochrome P450cam at atomic resolution. Science. 2000, 287: 1615-1622

64 Choi KS, Lai TH, Lee SY, Chan KS. Reduction of rhodium(III) porphyrin hydroxide to rhodium(II)porphyrin. Organometallics, 2011, 30 : 2633-2635 
65 Rana MS, Tamagake K. Formation of ferryl porphyrin by electrochemical reduction of iron porphyrin in aqueous solution. $J$ Electroanal Chem, 2005, 581: 145-152

66 Wei ZC, Ryan MD. Infrared spectroelectrochemical reduction of iron porphyrin complexes. Inorg Chem, 2010, 49: 6948-6954

67 Ou ZP, Kadish KM, Wenbo E, Shao JG, Sintic PJ, Ohkubo K, Fukuzumi S, Crossley MJ. Substituent effects on the site of electron transfer during the first reduction for gold (III) porphyrins. Inorg Chem, 2004, 43: 2078-2086

68 Hendrickson D, Kinnaird MG, Suslick KS. Photochemistry of (5,10,15,20-tetraphenylporphyrinato)iron(III) halide-complexes, Fe(TPP) (X). J Am Chem Soc, 1987, 109: 1243-1244

69 Hoshino M, Yasufuku K, Konishi S. Optical absorption and ESR spectra of monomeric rhodium(II) tetraphenylporphyrin in 2-methyltetrahydrofuran solution at 77 K. Inorg Chem, 1984, 23 (13): 1982-1984

70 Grinstaff MW, Hill MG, Birnbaum ER, Schaefer WP, Labinger JA, Gray HB. Structures, electronic properties, and oxidation-reduction reactivity of halogenated Iron porphyrins. Inorg Chem, 1995, 34: 4896-4902

71 Sun Y, Hu XB, Li HR, Jalbout AF. Metalloporphyrin-dioxygen interactions and the effects of neutral axial ligands. J Phys Chem C, 2009, 113: $14316-14323$

72 Guo CC, Chu MF, Liu Q, Liu Y, Guo DC, Liu XQ. Effective catalysis of simple metalloporphyrins for cyclohexane oxidation with air in the absence of additives and solvents. Appl Catal A: Gen, 2003, 246: 303-309

73 Cheung $\mathrm{CW}$, Chan KS. Base-promoted selective aryl C-Br and C-I bond cleavage by iridium (III) porphyrin: reduction of Ir(III)-OH to Ir(II) for metalloradical ipso substitution of aryl halogen bonds. Organometallics, 2011, 30: 4269-4283

74 Guo CC, Liu Q, Wang XT, Hu HY. Selective liquid phase oxidation of toluene with air. Appl Catal A: Gen, 2005, 282: 55-59

75 Ledon H. Iron porphyrin-catalyzed oxidation of cyclohexene. C R Acad Sci Paris, Série IIc 2, 1979, 288(1): 29-31

76 Tatsuno Y, Sekiya A, Tani K, Saito T. Factors affecting the oxygen atom transfer in metalloporphyrin-catalyzed epoxidation of cyclohexene, a model for P-450 catalyzed oxidation. Chem Lett, 1986, 889-892

77 Guo CC. Synthesis of $\mu$-oxo-bisiron(III)porphyrin compounds and their catalysis for cyclohexane hydroxylation. J Catal, 1998, 178: $182-187$

78 Guo CC, Li HP, Xu JB. Study of synthesis of $\mu$-oxo-bismanganese(III)porphyrin compounds and their catalysis for cyclohexane by PhIO. $J$ Catal, 1999, 185: 345

79 郭灿城, 朱申杰, 桂明德. [TPPFe(III) $]_{2} \mathrm{O}$ 的合成及其对细胞色素 P-450 的模拟. 化学学报, 1992, 50: 129-134

80 朱申杰, 桂明德, 郭灿城. $\mu$-氧-双四苯基卟吩合铁(III)在 $\mathrm{CH}_{2} \mathrm{Cl}_{2}$-氧化剂体系中的转化反应研究. 高等学校化学学报, 1989 , $10(11)$ : 1100-1104

81 Guo CC, Peng QJ, Liu Q, Jiang GF. Selective oxidation of ethylbenzene with air catalyzed by simple $\mu$-oxo dimeric metalloporphyrins under mild conditions in the absence of additives. J Mol Catal A: Chem, 2003, 192: 295-302

82 Hu HY, Jiang Q, Liu Q, Song JX, Lin WY, Guo CC. Catalysis of $\mu$-oxo-bis[porphyriniron(III)] for toluene oxidation with molecular oxygen. J Porphyrins Phthalocyanines, 2006, 10: 948-952

83 Guo CC, Liu XQ, Liu Y, Liu Q, Chu MF, Zhang XB. Studies of simple $\mu$-oxo-bisiron(III)-porphyrin as catalyst of cyclohexane oxidation with air in absence of cocatalysts or coreductants. J Mol Catal A: Chem, 2003, 192: 289-294

84 Collman JP, Chien AS, Eberspacher TA, Zhong M, Brauman JI. Competitive reaction of axial ligands during biomimetic oxygenations. Inorg Chem, 2000, 39: 4625-4629

85 Brulé E, Miguel YR. Supported metalloporphyrin catalysts for alkene epoxidation. Org Biomol Chem, 2006, 4: 599-609

86 Rocha Gonsalves AMd'A, Pereira M. State of the art in the development of biomimetic oxidation catalysts. J Mol Catal A: Chem, 1996, 113: 209-211

87 Nappa MJ, Tolman CA. Steric and electronic control of iron porphyrin catalyzed hydrocarbon oxidations. Inorg Chem, 1985, 24: 471 $1-4719$

88 阳卫军, 郭灿城, 毛彦利, 李国成. 单金属锰、铁卟啉对空气氧化 $\alpha$-蒎烯的催化作用及取代基效应. 高等学校化学学报, 2005, 26(9): 1695-1698

89 Połtowicz J, Tabor E, Pamin K, Haber J. Effect of substituents in the manganese $\mu$-oxo porphyrins catalyzed oxidation of cyclooctane with molecular oxygen. Inorg Chem Commun, 2005, 8: 1125-1127

90 Liu N, Jiang GF, Guo CC, Tan Z. Quantitative structure-activity relationship studies on ironporphyrin catalyzed cyclohexane oxidation with PhIO. J Mol Catal A: Chem, 2009, 304: 40-46

91 Alkordi MH, Liu YL, Larsen RW, Eubank JF, Eddaoudi M. Zeolite-like metal-organic frameworks as platforms for applications: On metalloporphyrin-based catalysts. J Am Chem Soc, 2008, 130: 12639-12641 
92 郭灿城, 桂明德, 朱申杰. 铁卟啉化合物的合成及其催化环己烷羟基化反应的研究. 有机化学, 1994, 14(2): 163-170

93 陈新斌, 郭灿城, 梁本喜, 饶宗海, 杨治国. 金属卟啉的合成及其对细胞色素 P-450 的模拟(XIV)——钴卟啉对环已烷的单充氧催化 作用. 高等学校化学学报, 1995, 16(7): 1051-1054

94 Nam W, Kim I, Kim Y, Kim C. Biomimetic alkane hydroxylation by cobalt(III) porphyrin complex and m-chloroperbenzoic acid. Chem Commun, 2001, 1262-1263

95 郭灿城, 郝旭东, 张晓兵, 梁本喜, 陈新斌. 磁场对铁卟啉仿生催化性能的影响. 高等学校化学学报, 1997, 18(6): 906-907

96 Nam W, Lim MH, Oh S-Y, Lee JH, Lee H J, Woo SK, Kim C, Shin W. Remarkable anionic axial ligand effects of iron(III) porphyrin complexes on the catalytic oxygenations of hydrocarbons by $\mathrm{H}_{2} \mathrm{O}_{2}$ and the formation of oxoiron(IV) porphyrin intermediates by m-chloroperoxybenzoic acid. Angew Chem Int Ed, 2000, 39: 3646-3649

97 Nam W, Lim M H, Oh S-Y. Effect of anionic axial ligands on the formation of oxoiron(IV) porphyrin intermediates. Inorg Chem, 2000, 39: 5572-5575

98 Nam W, Jin SW, Lim MH, Ryu JY, Kim C. Anionic ligand effect on the nature of epoxidizing intermediates in iron porphyrin complex-catalyzed epoxidation reactions. Inorg Chem, 2002, 41: 3647-3652

99 Nenoff TM, Showalter MC, Salaz KA. Supported metalloporphyrins catalyzed the oxidation of isobutane by dioxygen. J Mol Catal A: Chem, 1997, 121: 123-129

100 Evans S, Lindsay Smith JR. The oxidation of ethylbenzene by dioxygen catalysed by supported iron porphyrins derived from iron(III) tetrakis(phetafluorophenyl)porphyrin. J Chem Soc Perkin Trans 2, 2001, 174-180

101 Haber J, Matachowski L, Pamin K, Połtowicz J. Supported polyhalogenated metalloporphyrins as catalysts for the oxidation of cycloalkanes with molecular oxygen in Lyons system. Catal Today, 2004, 91-92: 195-198

102 Guo CC, Huang Guan, Zhang XB, Guo DC. Catalysis of chitosan-supported iron tetraphenylporphyrin for aerobic oxidation of cyclohexane in absence of reductants and solvents. Appl Catal A: Gen, 2003, 247: 261-267

103 Huang Guan, Luo J, DengC C, GuoYA, Zhao S K, Zhou H, Wei S. Catalytic oxidation of toluene with molecular oxygen over manganese tetraphenylporphyrin supported on chitosan. Appl Catal A: Gen, 2008, 338(1-2): 83-86

104 Guo CC, Huang G, Guo DC, Preparation of nitrogenous polysaccharide-supported ironporphyrins and their catalysis for the aerobic oxidation of cyclohexane. Kinet Catal, 2006, 47(1): 93-97

105 Liu CX, Liu Q, Guo, CC. Synthesis and catalytic abilities of silica-coated $\mathrm{Fe}_{3} \mathrm{O}_{4}$ nanoparticle bonded metalloporphyrins with different saturation magnetization. Catal lett, 2010, 138(1-2): 96-103

106 Liu CX, Liu Q, Guo CC, Tan Z. Preparation and characterization of novel magnetic nanocomposite-bonded metalloporphyrins as biomimetic nanocatalysts. J Porphyr Phthalocy, 2010, 14(9): 825-831

107 Guo CC, Song J-X, Chen X-B, Jiang G-F. A new evidence of the high-valent oxo-metal radical cation intermediate and hydrogen radical abstract mechanism in hydrocarbon hydroxylation catalyzed by metalloporphyrins. J Mol Catal A: Chem, 2000, 157: 31-40

108 Fokin AA, Schreiner PR. Selective Alkane transformations via radicals and radical cations: insights into the activation step from experiment and theory. Chem Rev, 2002, 102(5): 1551-1594

109 郭灿城. 金属卟啉的合成及其对细胞色素 P-450 的模拟. 12. $\mu$-氧-双铁(III)卟啉系列化合物对环已烷的单充氧催化作用. 化学学报, 1994, 52: 367-372

110 郭灿城, 张尚, 雷裕武. 亚碘酰苯氧化单和双(卟啉铁)反应的取代基效应研究. 化学学报, 1993, 51: 928-932

111 郭灿城, 丁亮中, 梁本喜, 陈新斌. $\mu$-氧代双锰(III)卟啉氧化反应及取代基效应研究. 高等学校化学学报, 1996, 17(4): 558-561

112 郭灿城, 刘晓宇, 杨明生, 朱申杰, 桂明德. 金属卟啉自氧化反应研究. 高等学校化学学报, 1991, 12(12): 1617-1619

113 Nam W. High-valent iron(IV)-oxo complexes of heme and non-heme ligands in oxygenation reactions. Acc Chem Res, 2007, 40: 522-531

114 Groves JT, Shalyaev K, Lee J. Oxometalloporphyrins in oxidative catalysis. In: Kadish KM, Smith KM, Guilard R. Eds. Porphyrin Handbook. vol. 4. Biochemistry and Binding: Activation of Small Moleculars. New York: Academic Press, 2000, 17-40

115 Moore KT, Horvath IT, Therien MJ. Mechanistic studies of (porphinato)iron-catalyzed isobutane oxidation, comparative studies of three classes of electron-deficient porphyrin catalysts. Inorg Chem, 2000, 39(15): 3125-3139

116 Labinger JA. A simplified model for catalyzed isobutane autoxidation: implications for the mechanism of catalysis by halogenated porphyrin complexes. Catal Lett, 1994, 26(1-2): 95-99

117 Haber J, Matachowski L, Pamin K, Połtowicz J. The effect of peripheral substituents in metalloporphyrins on their catalytic activity in Lyons system. J Mol Catal A: Chem, 2003, 198: 215-221

118 Grinstaff MW, Hill MG, Labinger JA, Gray HB. Mechanism of catalytic oxygenation of alkanes by halogenated iron porphyrins. Science, 1994, 264: 1311-1313 
119 Hu BY, Yuan YJ, Xiao J, Guo CC, Liu Q, Tan Z, Li QH. Rational oxidation of cyclohexane to cyclohexanol, cyclohexanone and adipic acid with air over metalloporphyrin and cobalt salt. J Porphyrins Phthalocyanines, 2008, 12(1): 27-34

120 Guo CC, Liu XQ, Liu Q, Liu Y, Chu MF, Lin WY. First industrial-scale biomimetic oxidation of hydrocarbon with air over metalloporphyrins as cytochrome P-450 monooxygenase model and its mechanistic studies. J Porphyr Phthalocyan, 2009, 13(12): $1250-1254$

121 Watanabe Y. Alternatives to the oxoferryl porphyrin cation radical as the proposed reactive intermediate of cytochrome P450: Two-electron oxidized Fe(III) porphyrin derivatives. J Biol Inorg Chem, 2001, 6(8): 846-56

122 Jayaraj K, Terner J, Gold A, Roberts DA, Austin RN, Mandon D, Weiss R, Bill E, Müther M, Trautwein AX. Influence of meso substituents on electronic states of (oxoferryl)porphyrin $\pi$-cation radicals. Inorg Chem, 1996, 35:1632-1640

123 Fujii H. Electronic structure and reactivity of high-valent oxo iron porphyrins. Coord Chem Rev, 2002, 226: 51-60

124 Recupero F, Punta C. Free radical functionalization of organic compounds catalyzed by N-hydroxyphthalimide. Chem Rev, 2007, 107: 3800-3842

125 Ishii Y, Sakaguchi S, Iwahama T. Innovation of hydrocarbon oxidation with molecular oxygen and related reactions. Adv Synth Catal, 2001, 343: 393-427

126 Chavez FA, Nguyen CV, Olmstead MM, Mascharak PK. Synthesis, properties, and structure of a stable cobalt(III) alkyl peroxide complex and its role in the oxidation of cyclohexane. Inorg Chem, 1996, 35: 6282-6291

127 Thomas JM, Raja R. Catalytically active centres in porous oxides: Design and performance of highly selective new catalysts. Chem Commun, 2001, 675-687

128 Thomas JM, Raja R. Innovations in oxidation catalysis leading to a sustainable society. Catal Today, 2006, 117: 22-31

129 Vanoppen DL, De Vos DE, Genet MJ, Rouxhet PG, Jacobs PA. Cobalt-containing molecular sieves as catalysts for the low conversion autoxidation of pure cyclohexane. Angew Chem Int Ed Eng, 1995, 34(5): 560-563

130 Chen J-R, Yang H-H, and Wu X-H. A novel process of autoxidation of cyclohexane using pure oxygen. Org Pro Res Dev, 2004, 8: 252-255

131 郭灿城, 张晓兵, 侯连伯, 徐建兵, 郝旭东, 郭广明, 梁本喜, 陈新斌. 金属卟啉催化环已烷羟基化反应中环已酮的形成机理研究. 化学学报, 1998, 56: 489-494

132 Dyker G. Handbook of X-HTransformations: Applications in Organic Synthesis. New York: WILEY-VCH, 2005

133 Suslick KS. Shape selective oxidation by metalloporphyrins. In: Kadish KM, Smith KM, Guilard R, Eds. Porphyrin Handbook. vol. 4. Biochemistry and Binding: Activation of Small Moleculars. New York: Academic Press, 2000, 41-63

134 郭灿城, 张晓兵, 欧阳玉祝, 李和平. 乙酰葡萄糖氧代金属卟啉的合成及其对环已烷羟基化反应的催化作用. 高等学校化学学报, 2000, 21(2) : 227-232

135 Xu KW, Ma JY, Jiang Q, Hu HY, Guo CC. Selective catalysis of manganeseporphyrins on aerobic oxidation of different carbon-hydrogen bonds of methyl cyclohexane. J Mol Catal A: Chem, 2006, 243, 194-197

136 马金勇, 郭灿城. 金属卟啉催化空气氧化甲基环已烷制备甲基环己醇和甲基环己酮. 化工学报, 2005, 56(5): 835-840

137 梁学博, 胡伯羽, 袁永军, 刘强, 郭灿城. 金属卟啉催化空气氧化环已烷反应的工艺优化. 化工学报, 2007, 58(3): 794-800

138 Yuan Y, Ji HB, Chen YX, Han Y, Song XF, She YB, Zhong RG. Oxidation of cyclohexane to adipic acid using Fe-porphyrin as a biomimetic catalyst. Org Proc Res Dev, 2004, 8(3): 418-420

139 Guo CC, Huang G, Li ZP, Song JX. Study of the selective catalysis of metalloporphyrins for 2-methyl-butane oxidation with PhIO under mild conditions. J Mol Catal A: Chem, 2001, 170(1-2): 43-49

140 郭灿城, 张晓兵, 宋建新, 李和平. 乙酰糖基金属卟啉的合成及其对烷烃温和氧化的选择性催化作用. 化学学报, 2000, 58(3): 332-337

141 徐建兵. 金属卟啉化合物的合成及其对烷烃温和氧化的催化作用研究, 湖南大学硕士论文, 1999

142 Kameyama H, Narumi F, Hattori T, Kameyama H. Oxidation of cyclohexene with molecular oxygen catalyzed by cobalt porphyrin complexes immobilized on montmorillonite. J Mol Catal A: Chem, 2006, 258: 172-177

143 Paulson DR, Ullman R, Sloane RB, Closs GL. Metalloporphyrin catalysed epoxidations with molecular oxygen. J Chem Soc, Chem Commun, 1974, 186-187

144 刘文, 刘强, 郭灿城. 钴卟啉对空气氧化环已烯合成环已烯酮的催化作用. 化工学报, 2004, 55(9): 1537-1540

145 Guo CC, Yang WJ, Mao YL. Selectively aerobic oxidation of C=C and allylic C-H bonds in $\alpha$-pinene over simple metalloporphyrins. $J$ Mol Catal A: Chem, 2005, 226: 279-284

146 阳卫军, 郭灿城, 毛彦利, 李国成. 单金属锰、铁卟啉对空气氧化蒎烯的催化作用及取代基效应. 高等学校化学学报. 2005, 26(9): 
1690-1694

147 Rebelo SLH, Simões MMQ, Neves MGPMS, Cavaleiro JAS. Oxidation of alkylaromatics with hydrogen peroxide catalysed by manganese(III) porphyrins in the presence of ammonium acetate. J Mol Catal A: Chem, 2003, 201(1-2): 9-22

148 LiYF, Yang XH, Jiang GF, Liu Q, Song JX, Guo CC. Toluene oxyfunctionalization with air over metalloporphyrins and reaction condition optimization. Chin J Chem Eng, 2007, 15(3): 453-457

149 Jiang Q, Hu HY, Guo CC, Liu Q, Song JX, Li QH. Aerobic liquid-phase oxidation of p-xylene over metalloporphyrins, J Porphyri Phthalocyan, 2007, 11: 524-530

150 Jiang Q, Xiao Y, Tan Z, Li QH, Guo CC. Aerobic oxidation of p-xylene over metalloporphyrin and cobalt acetate: Their synergy and mechanism. J Mol Catal A: Chem, 2008, 285(1-2): 162-168

151 Xiao Y, Luo WP, Zhang XY, Guo CC, Liu Q, Jiang GF, Li QH. Aerobic oxidation of p-toluic acid to terephthalic acid over $\mathrm{T}(\mathrm{p}-\mathrm{Cl}) \mathrm{PPMnCl} / \mathrm{Co}(\mathrm{OAc})_{2}$ under moderate conditions. Catal Lett, 2010, 134: 155-161

152 Schuchardt U, Carvalho WA, Spinacé EV. Why is it interesting to study cyclohexane oxidation. Synlett, 1992, 713-718

153 郭灿城, 刘强, 张晓兵. 催化空气氧化烷烃和环烷烃方法. CN 00113225. 3, 2003-07-30

154 郭灿城, 刘强, 刘洋, 张晓兵. 金属卟啉催化空气氧化环已烷的方法. CN 02139709.0, 2005-03-20

155 Shimizu A, Tanaka K, Fujimori M. Abatement technologies for $\mathrm{N}_{2} \mathrm{O}$ emissions in the adipic acid industry. Chemosphere-Global Change. Science, 2000, 2: 425-434

156 郭灿城, 刘强, 王旭涛. 空气氧化六碳环化合物制备已二酸的方法. CN 03118249. 6, 2005-09-04

157 郭灿城, 郭栋才, 罗伟平, 邓伟, 刘强, 江国防. 环已烷空气氧化制备环已醇、环已酮和已二酸的工艺及设备. CN 200610031689. X, 2008-06-11

158 郭灿城, 徐庆利, 罗伟平, 刘强. 催化空气氧化环己烷制备已二酸的工艺和设备. CN 200810032099.8, 2011-04-20

159 魏文德. 有机化工原料大全(中卷). 北京: 化学工业出版社, 1999, 960

160 Kantam ML, Sreekanth P, Rao KK, Kumar TP, Rao BPC, Choudary BM. An improved process for selective liquid-phase air oxidation of toluene. Catal Lett, 2002, 81(3-4) : 223-232

161 郭灿城, 王旭涛, 刘强. 选择性催化空气氧化甲苯和取代甲苯成醛和醇的方法. CN 03118066. 3, 2009-06-03

162 郭灿城, 罗伟平, 刘连冲, 刘强, 邓伟. 多极握拳化甲苯制备苯甲醛、苯甲醇的工艺及设备. CN 200910305128, 2012-05-30

\title{
Theoretical studies and industrial applications of oxidative activation of inert $\mathrm{C}-\mathrm{H}$ bond by metalloporphyrin-based biomimetic catalysis
}

\section{LIU Qiang, GUO CanCheng*}

Advanced Catalytic Engineering Research Center of the Ministry of Education; College of Chemistry and Chemical Engineering of Hunan University, Changsha 410082, China

*Corresponding author (email: ccguo@hnu.edu.cn)

\begin{abstract}
High costs and low catalytic efficiency of metalloporphyrins, which are an analogue of cytochrome P450 enzyme, are the bottlenecks in the industrialization of biomimetic hydrocarbon oxidation reactions. The basic principle and research technique of physical organic chemistry were applied to the process of biomimetic oxidation of hydrocarbon catalyzed by metalloporphyrins. This biomimetic technology could be adapted to bulk chemicals production by developing the new methods for efficient scale-up synthesis of metalloporphyrins, new pathways for molecular oxygen activation on an industrial scale and new approaches to elevate the catalytic efficiency of metalloporphyrins. This review mainly focuses on research carried out in our group.
\end{abstract}

Keywords: metalloporphyrin, biomimetic oxidation, $\mathrm{C}-\mathrm{H}$ bond activation, mechanism, catalysis 